\title{
A 3-V Fully Differential Distributed Limiting Driver for 40-Gb/s Optical Transmission Systems
}

\author{
Douglas S. McPherson, Member, IEEE, Florin Pera, Member, IEEE, Mihai Tazlauanu, and \\ Sorin P. Voinigescu, Senior Member, IEEE
}

\begin{abstract}
A fully differential $40-\mathrm{Gb} / \mathrm{s}$ electro-absorption modulator driver is presented. Based on a distributed limiting architecture, the circuit can supply up to $3.0-\mathrm{V}_{\mathrm{pp}}$ (peak-to-peak) per side in a $50-\Omega$ load at data rates as high as $44 \mathrm{~Gb} / \mathrm{s}$. Both the input and the output are internally matched to $50 \Omega$ and exhibit return loss of better than $10 \mathrm{~dB}$ up to $50 \mathrm{GHz}$. Additional features of the

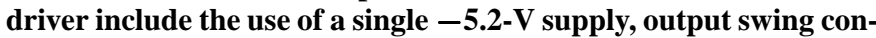
trol (1.7-3.0- $\mathrm{V}_{\mathrm{pp}}$ per side), dc output offset control $(-0.15 \mathrm{~V}$ to $-1.1 \mathrm{~V})$, and pulsewidth control (30\% to $66 \%)$. The driver architecture was optimized based on a comprehensive analytical derivation of the frequency response of cascaded source-coupled field-effect transistor logic blocks using both single and double source-follower topologies.
\end{abstract}

Index Terms-Analog integrated circuits, differential amplifiers, high-speed integrated circuits, integrated circuit design, modulator driver, optical fiber communication, optical transmitters, source-coupled FET logic (SCFL).

\section{INTRODUCTION}

$\mathbf{H}$ IGH-PERFORMANCE low-cost physical layer integrated circuits are essential for the successful implementation of next-generation $40-\mathrm{Gb} / \mathrm{s}$ optical communication systems. To realize an advantage over current wavelength-division-multiplexing (WDM) technology, these data rates must be achieved at the single-channel level. This prerequisite imposes significant technological demands on the front-end electro-optical interface (EOI) components.

Modulator drivers are a case in point. Not only must they operate at the high data rates, but they must deliver high voltage levels as well. For conventional Mach-Zehnder (MZ) or electro-absorption (EA) devices to achieve adequate extinction ratios and, thus, reach, these modulators must be driven by signals having a swing of at least $3-5 \mathrm{~V}_{\mathrm{pp}}$ (peak-to-peak) per side. For $40-\mathrm{Gb} / \mathrm{s}$ driver applications, the only devices that have so far demonstrated the requisite characteristics are GaAs pseudomorphic high electron mobility transistors (pHEMTs) and InP double heterojunction bipolar transistors (DHBTs) [1]. SiGe HBTs with $f_{T}$ values beyond $210 \mathrm{GHz}$ have also been suggested, due to their reproducibility, high yield, and low cost [2]-[4]. However, there are significant concerns regarding their long-term reliability because they exhibit base-emitter $\left(\mathrm{BV}_{\mathrm{CEO}}\right)$ and base-collector $\left(\mathrm{BV}_{\mathrm{CBO}}\right)$ breakdown voltages

Manuscript received January 15, 2003; revised April 4, 2003.

D. S. McPherson and M. Tazlauanu are with Quake Technologies Inc., Ottawa, ON K2K 2T8, Canada (e-mail: douglasm@quaketech.com).

F. Pera is with Insyte Corporation, Ottawa, ON K2K 3C9, Canada.

S. P. Voinigescu is with the Department of Electrical and Computer Engineering, University of Toronto, Toronto, ON M5S 3G4, Canada.

Digital Object Identifier 10.1109/JSSC.2003.815924 lower than 2 and $6 \mathrm{~V}$, respectively. They also operate at high current densities of $6 \mathrm{~mA} / \mu \mathrm{m}^{2}$ or more and suffer from significant self-heating at peak $f_{\mathrm{T}}$ bias [4]. In the case of an output stage having $3 \mathrm{~V}_{\mathrm{pp}}$, the SiGe HBT would be biased beyond $\mathrm{BV}_{\mathrm{CEO}}$, an operating region in which reliability is not guaranteed by manufacturers.

To date, almost all of the reported $40-\mathrm{Gb} / \mathrm{s}$ modulator drivers are based on AlGaAs-InGaAs pHEMTs with gate lengths in the range of 0.1 to $0.2 \mu \mathrm{m} \mathrm{[5],} \mathrm{[6].} \mathrm{In} \mathrm{spite} \mathrm{of} \mathrm{its} \mathrm{low} f_{\mathrm{T}}$ of approximately $100 \mathrm{GHz}$, this technology is by far the most attractive for this application. Not only does it have a high breakdown voltage of $6 \mathrm{~V}$ and an $f_{\mathrm{MAX}}$ of approximately $200 \mathrm{GHz}$, it has proven yield and reliability, as well as the capacity to be manufactured on 6-in wafers. To overcome the $f_{\mathrm{T}}$ limitation, however, the output stage of the driver must be based on a distributed amplifier topology, possibly with cascode gain stages. This will extend the high-frequency performance of the device, ensure good broad-band input/output impedance matching, and also achieve the required output swing.

In this paper, the first full-featured differential GaAs pHEMT modulator driver is presented. It consists of a lumped predriver circuit followed by a five-stage distributed amplifier (DA). Compared to previously reported $40-\mathrm{Gb} / \mathrm{s}$ drivers, the latter section of the present design is based on a differential distributed limiting architecture, rather than the more conventional single-ended linear approach. As a result, the circuit can significantly exceed its small-signal bandwidth when operated under large-signal conditions. The limiting architecture also simplifies the inclusion of output swing control, dc output offset control, and pulsewidth control.

\section{Device Modeling}

Unlike conventional linear drivers, which are based on a relatively small number of device geometries operated in saturation, the differential limiting architecture calls for a nonlinear device model that scales accurately over a wide range of gate widths and bias levels. In order to develop a realistic specification for the driver's performance, it should scale with temperature as well. To this end, a fully scalable nonlinear model was developed using Agilent's EEHEMT implementation. The nominal model values were derived from S-parameters and dc $I-V$ curves that were measured over five different gate widths and using conventional extraction techniques for both the extrinsic and intrinsic circuit elements. By carefully adjusting the model parameters based on the five extractions, it is possible to obtain good agreement over all of the measured gate geometries. 


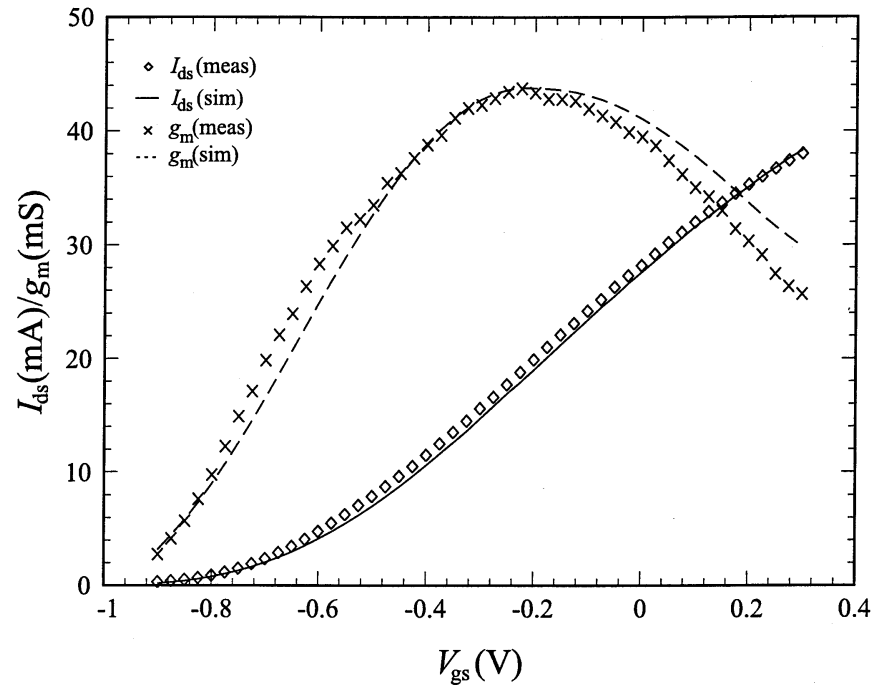

Fig. 1. Measured versus simulated drain current and transconductance for a $2 \times 40 \mu \mathrm{m} \mathrm{GaAs}$ pHEMT biased at $V_{\mathrm{ds}}=2.5 \mathrm{~V}$.

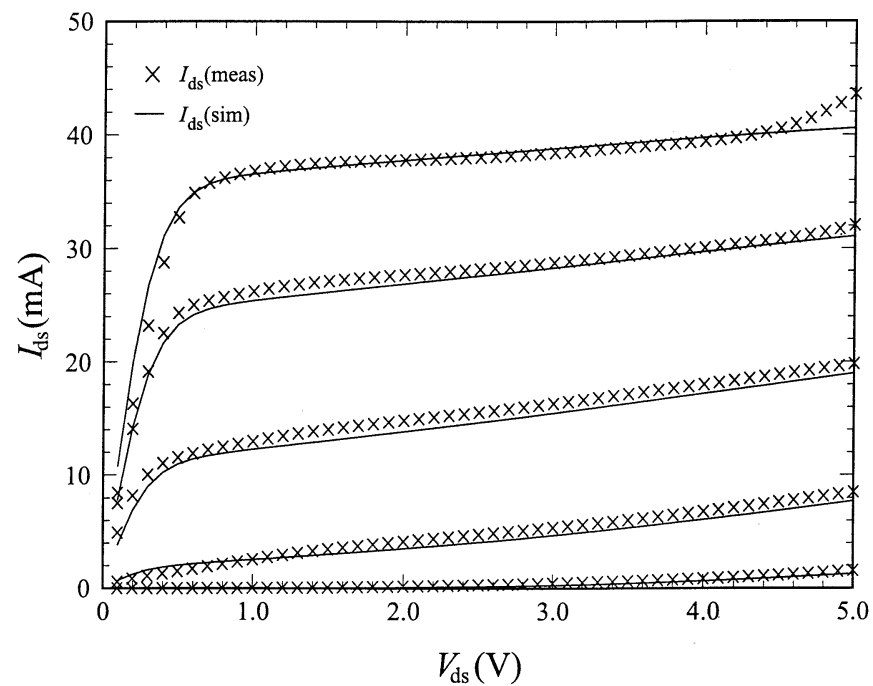

Fig. 2. Measured versus simulated dc output characteristics for a $2 \times 40 \mu \mathrm{m}$ GaAs pHEMT.

As an example of the quality of the extracted model, Figs. 1 and 2 present measured versus simulated dc characteristics for a transistor having a $2 \times 40 \mu \mathrm{m}$ gate geometry. By scaling the model parameters with finger width and number of fingers, a similar fit can be obtained for all five gate geometries. Fig. 3 compares the measured and simulated $f_{\mathrm{T}}-I_{\mathrm{ds}}$ characteristics at $V_{\mathrm{ds}}=2.5 \mathrm{~V}$ for different transistor sizes, while peak $f_{\mathrm{T}}$ values are presented in Fig. 4 as a function of gate width and temperature for $V_{\mathrm{ds}}=1.5 \mathrm{~V}$ and $V_{\mathrm{gs}}=-0.1 \mathrm{~V}$. Over the entire range, the measured and modeled peak $f_{\mathrm{T}}$ values are no more than $10 \%$ apart. The temperature dependence in the model has been extracted empirically from device measurements made at $18^{\circ} \mathrm{C}$ and $100^{\circ} \mathrm{C}$. Table I summarizes the main scalable model parameters that characterize the small-signal equivalent circuit of the transistor.

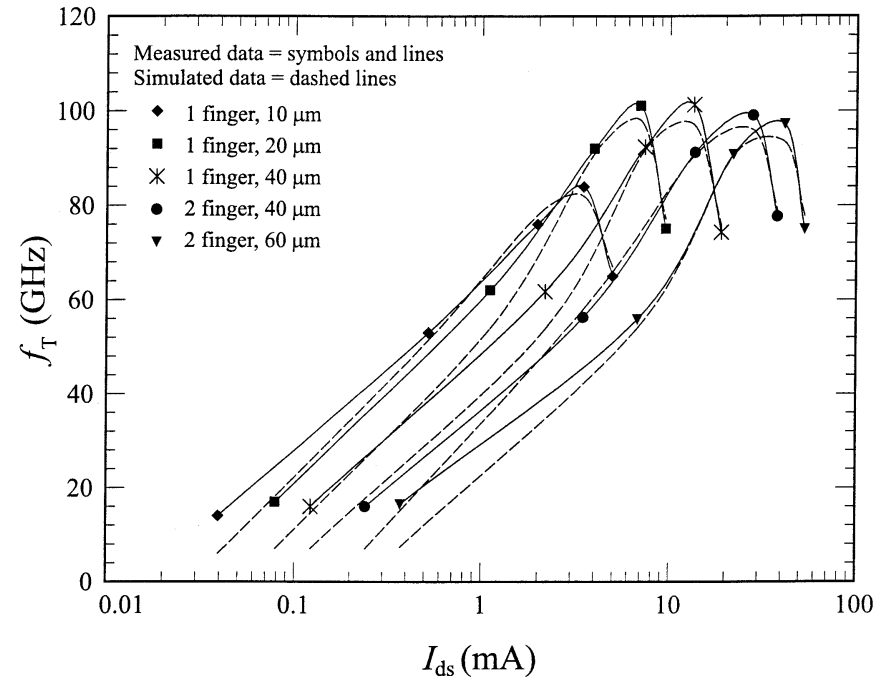

Fig. 3. Measured versus simulated $f_{\mathrm{T}}-I_{\mathrm{ds}}$ characteristics of $1 \times 10 \mu \mathrm{m}$, $1 \times 20 \mu \mathrm{m}, 1 \times 40 \mu \mathrm{m}, 2 \times 40 \mu \mathrm{m}$, and $2 \times 60 \mu \mathrm{m} \mathrm{GaAs}$ pHEMTs at $18{ }^{\circ} \mathrm{C}$ and $V_{\mathrm{ds}}=2.5 \mathrm{~V}$.

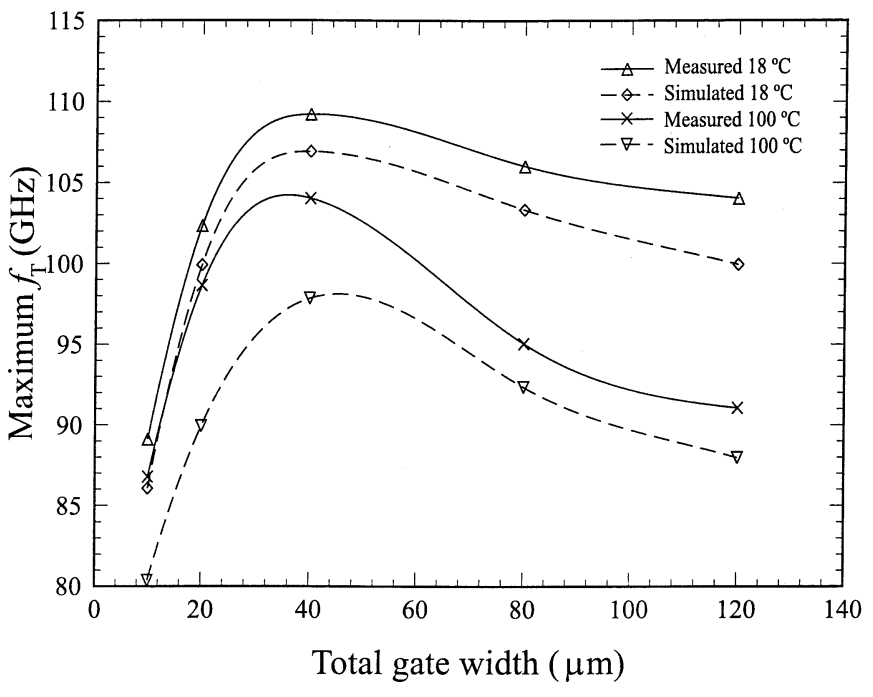

Fig. 4. Measured and simulated maximum $f_{\mathrm{T}}$ values versus total gate width and temperature for $V_{\mathrm{ds}}=1.5 \mathrm{~V}$ and $V_{\mathrm{gs}}=-0.1 \mathrm{~V}$.

\section{CiRCUIT Design}

\section{A. General Architecture}

A block diagram of the differential limiting driver is shown in Fig. 5. It includes three gain blocks, namely, a lumped input amplifier, a lumped middle-stage amplifier, and a distributed output amplifier block, all of which operate from a single $-5.2 \mathrm{~V}$ supply. The lumped amplifier blocks and the distributed amplifier sections all consist of a double source-follower stage with level-shifting diodes and a differential inverter. To enable the modulator to achieve its optimal performance, the driver also includes variable output amplitude (VOA), variable EA modulator offset (VEA), and adjustable duty-cycle distortion (DCD) or pulsewidth control.

The input stage features on-chip $50-\Omega$ resistors to provide good input match and is self-biased at a level of $-4 \mathrm{~V}$. For an input signal of $0.5 \mathrm{~V}_{\mathrm{pp}}$ per side, this stage provides an output swing of $1.0 \mathrm{~V}_{\mathrm{pp}}$ per side. This signal is then amplified and 
TABLE I

0.15- $\mu \mathrm{m}$ GaAs pHEMT SMALl-Signal MOdel PARAMETERS

\begin{tabular}{ccccccc}
\hline$I_{\mathrm{ds}} / \mathrm{mm}$ & $g_{\mathrm{m}} / \mathrm{mm}$ & $g_{\mathrm{ds}} / \mathrm{mm}$ & $C_{\mathrm{gs}} / \mathrm{mm}$ & $C_{\mathrm{gd}} / \mathrm{mm}$ & $C_{\mathrm{ds}} / \mathrm{mm}$ & $C_{\mathrm{sb}} / \mathrm{mm}$ \\
\hline \hline $200 \mathrm{~mA}$ & $530 \mathrm{mS}$ & $62.5 \mathrm{mS}$ & $940 \mathrm{fF}$ & $90 \mathrm{fF}$ & $72.6 \mathrm{fF}$ & $82.5 \mathrm{fF}$ \\
\hline
\end{tabular}

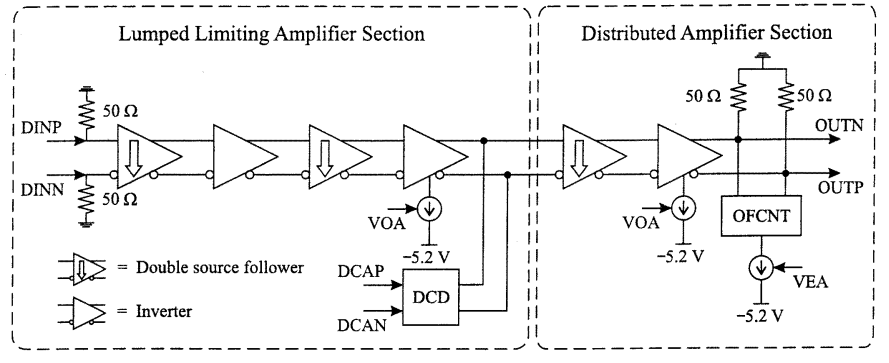

Fig. 5. Block diagram of the $40-\mathrm{Gb} / \mathrm{s}$ EA modulator driver illustrating the lumped and distributed sections.

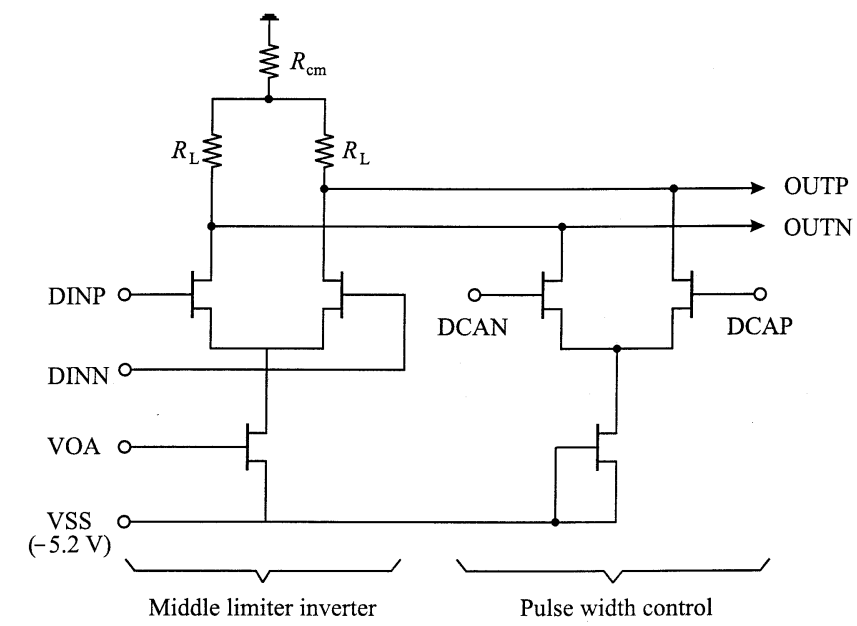

Fig. 6. Middle-stage inverter showing pulsewidth and output amplitude control function implementation.

limited to $1.4 \mathrm{~V}_{\mathrm{pp}}$ per side by the middle stage. The distributed amplifier has an overall gain of approximately $7 \mathrm{~dB}$ per side and limits the output swing to a maximum of $3 \mathrm{~V}_{\mathrm{pp}}$ per side.

\section{B. Middle-Stage Amplifier Block}

The schematic for the middle-stage amplifier block is shown in Fig. 6. To avoid any reflections with the DA, the load resistors $R_{\mathrm{L}}$ are matched to the characteristic impedance of the DA's input transmission lines, which is greater than $50 \Omega$. The common-mode resistor $R_{\mathrm{cm}}$ is used to set the dc input level for the DA. The block also includes the elements required for varying the output amplitude and pulsewidth. The former is achieved by adjusting the level supplied to the gate of the inverter current source via the VOA input. The pulsewidth control feature is implemented using a second differential pair connected in parallel with the middle-stage inverter. By default, the DCAP and DCAN pads are biased at the same level and cause the differential pair to sink equivalent amounts of current. As shown in Fig. 7(a) and (b), unbalancing them will introduce a dc offset $V_{\text {offset }}$ between the middle-stage output signals. If the two signals are then hard-limited, the effect is to lengthen the

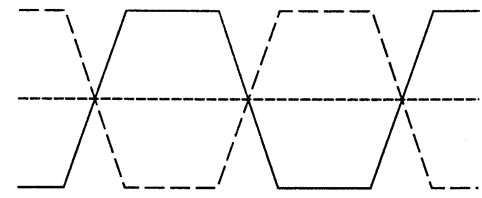

(a)

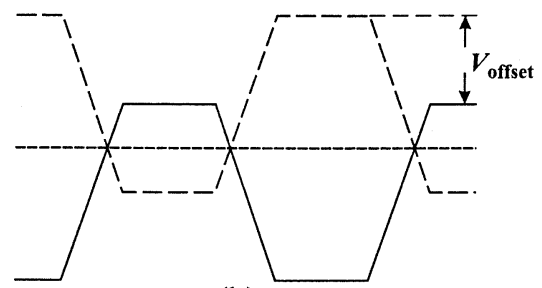

(b)

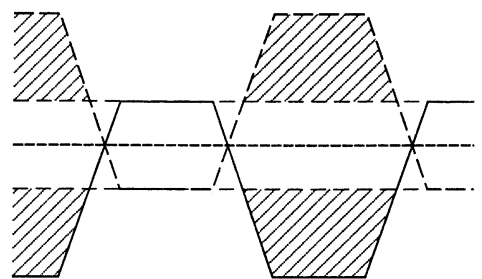

(c)

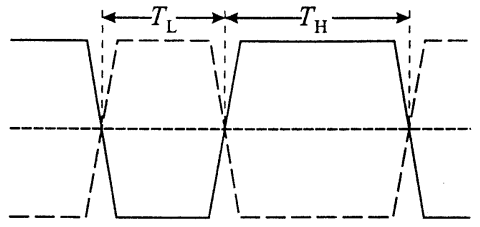

(d)

Fig. 7. Pulsewidth control function signal flow. (a) Signal at the input of the middle limiter inverter. (b) Signal at the output of the middle limiter inverter after applying a dc offset through the DCAP and DCAN control inputs. (c) Illustration of the amplitude limiting function of the next stage. (d) Resulting signal with modified pulsewidth at the output of the next limiting stage.

high pulse in relation to the low pulse (or vice versa), as illustrated in Fig. 7(c) and (d). The dc offset and pulsewidth variation $\Delta t$ can be expressed as

$$
\begin{gathered}
V_{\text {offset }}=\Delta I_{\mathrm{pwc}} R_{\mathrm{L}} \\
\Delta t=\frac{V_{\text {offset }}}{2 \mathrm{SL}}
\end{gathered}
$$

where $\Delta I_{\text {pwc }}$ is the difference in the currents sunk by the two branches of the second differential pair and SL is the slope of the rising and falling edges of the signal pulse. This pulsewidth control scheme only works if the rise and fall times are commensurate with the pulse half period and if it is applied between two limiting circuits, which in this case are the middle-stage and the DA.

\section{Distributed Amplifier Block}

Although the 0.1-0.2 $\mu \mathrm{m}$ gate-length GaAs pHEMT has a gate-to-drain breakdown voltage of approximately $-6 \mathrm{~V}$, its $f_{\mathrm{T}}$ 


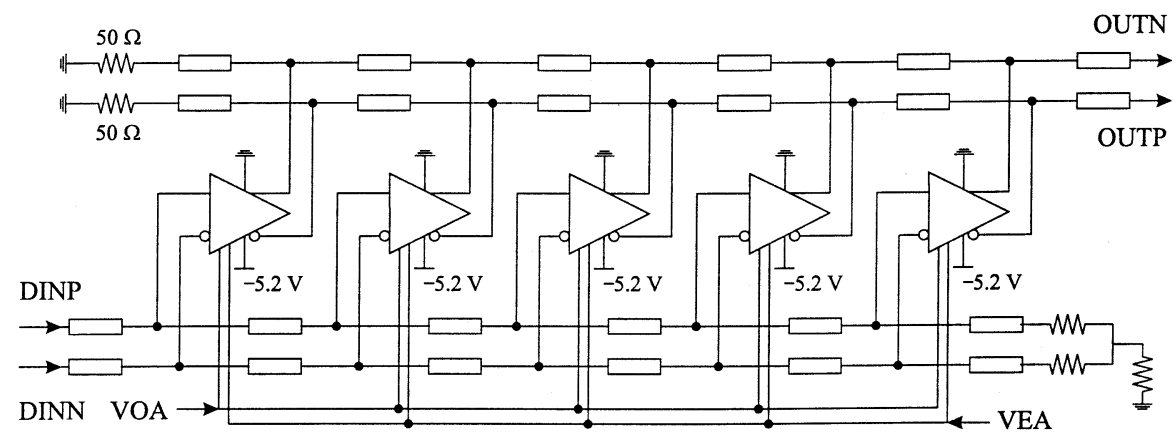

Fig. 8. Block diagram of the distributed amplifier section.

of $100-110 \mathrm{GHz}$ and maximum available gain (MAG) of $15 \mathrm{~dB}$ at $50 \mathrm{GHz}$ make it, at best, a marginal device for $40-\mathrm{Gb} / \mathrm{s}$ applications. For a dc-coupled circuit matched to $50 \Omega$ and having an output swing of $3 \mathrm{~V}_{\mathrm{pp}}$ per side, the required modulation current is $I_{T}=120 \mathrm{~mA}_{\mathrm{pp}}$. Although it is possible to achieve this specification using a lumped output stage at $10 \mathrm{~Gb} / \mathrm{s}$ [7], a simple analytical derivation indicates that this is not so at $40 \mathrm{~Gb} / \mathrm{s}$. Based on the model parameters from Table I, the size of the transistor $\left(W_{\mathrm{T}}\right)$ required to switch $120 \mathrm{~mA}_{\mathrm{pp}}$ into the on- and off-chip $50-\Omega$ loads is

$$
W_{\mathrm{T}}=\frac{I_{\mathrm{T}}}{2 I_{\mathrm{ds}} / \mathrm{mm}}=450 \mu \mathrm{m} .
$$

Summing the transistor's parasitic capacitances $C_{\mathrm{ds}}$ and $C_{\mathrm{db}}$, the on-chip 50- $\Omega$ load resistor's capacitance $C_{\mathrm{rb}}$, the interconnect capacitance $C_{\mathrm{W}}$, and the pad capacitance $C_{\mathrm{pad}}$ gives a total output load capacitance $C_{\mathrm{L}}$ of

$$
C_{\mathrm{L}}=C_{\mathrm{ds}}+C_{\mathrm{db}}+C_{\mathrm{rb}}+C_{\mathrm{W}}+C_{\mathrm{pad}} \approx 270 \mathrm{fF}
$$

and a 3-dB bandwidth of

$$
f_{3 \mathrm{~dB}}=\frac{1}{\pi R_{\mathrm{L}} C_{\mathrm{L}}}=23 \mathrm{GHz}
$$

It should be noted that this output pole does not include the added capacitance required to implement the dc output offset control function.

One solution to this problem is to use a distributed amplifier configuration. Not only will this mitigate the size-versus-speed constraint, but it also has the added benefit of excellent output return loss. To extend the bandwidth further still, the distributed amplifier block is designed to operate in a limiting mode. This allows the driver to accommodate data rates significantly beyond that predicted by its small-signal bandwidth. Such an approach has proved successful for 10-Gb/s drivers [8].

The block diagram of the five-stage differential distributed limiting amplifier is shown in Fig. 8, and the adjustable output amplitude and dc offset control elements of each stage are shown in Fig. 9. By distributing the elements of the latter control feature in each stage of the DA and by implementing it with high-impedance cascoded transistors, the parasitic capacitance introduced is both minimized and absorbed into the artificial output transmission lines. The output level is directly affected by the amount of current that the control transistors draw through the DA loads and can be varied by changing the level applied to the VEA pad. The adjustable output amplitude

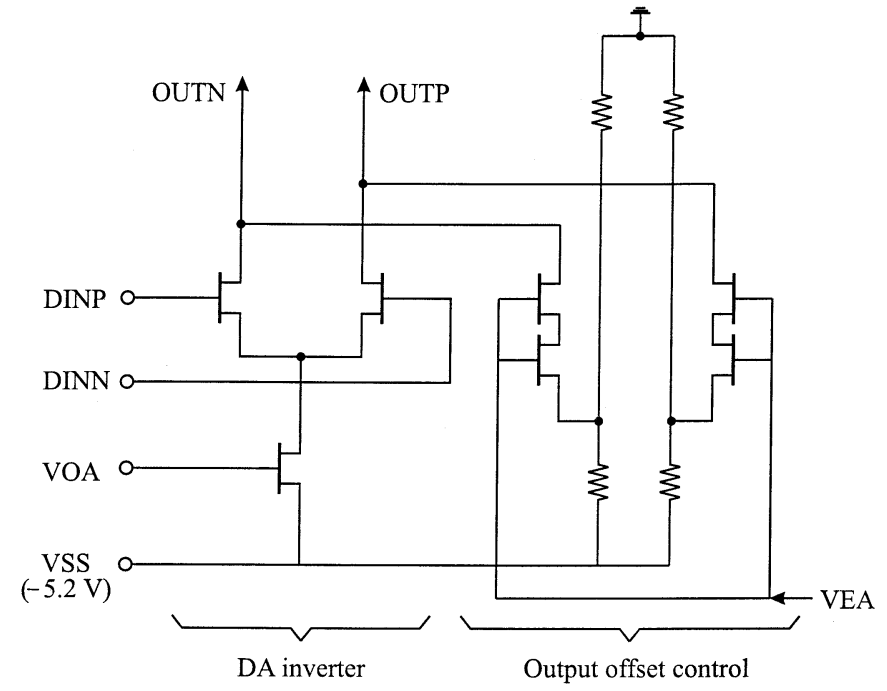

Fig. 9. Distributed amplifier inverting stage showing the output offset and amplitude control function implementations.

is controlled from the VOA pad and operates on the same principle as, and in conjunction with, the middle-stage amplitude control feature. Both techniques have been applied previously for $10-\mathrm{Gb} / \mathrm{s}$ EA modulator drivers [9].

\section{Choice of Gain-Stage Topology}

Industry practice has demonstrated that if the (bipolar) transistor cutoff frequency is at least four times higher than the bit rate, it is possible to achieve adequate bandwidth and input impedance with a chain of basic gain blocks consisting of a single source/emitter follower and an inverter stage (SSF-INV). By appropriately scaling the size of the transistor and tail current in each gain block from the output to the input of the amplifier, the required output swing and bit rate can be obtained with the minimum possible power dissipation. In cases where the $f_{\mathrm{T}}$ of the process is considerably less than four times the bit rate or where parasitic capacitance to ground is expected to be a major concern, additional source/emitter-follower buffering must be introduced in order to provide adequate compensation.

Depletion-mode pHEMTs, such as the ones used in the present design, further complicate the problem because they require level-shifting diodes to provide headroom for the large signal swings at the inverter outputs. In order to lessen their impact on the bandwidth of the gain block, high-frequency bypass capacitors must be included in parallel. Since both they 


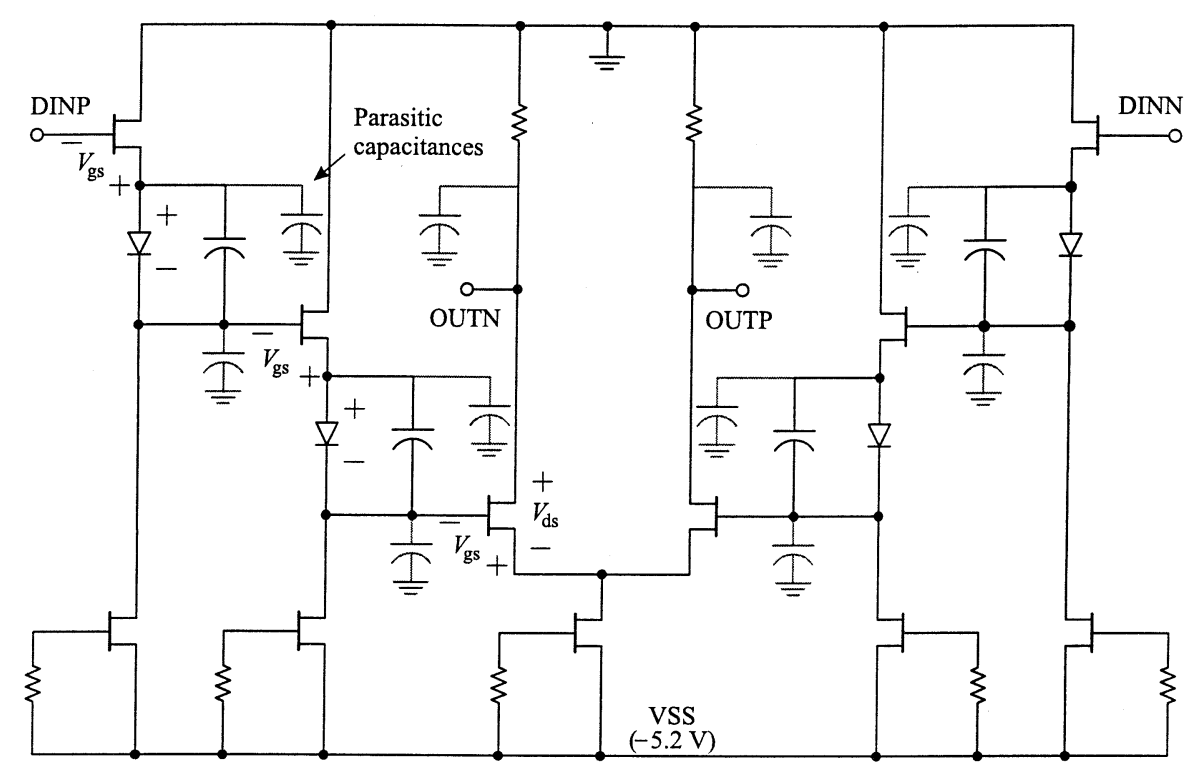

Fig. 10. Basic DSF-INV gain block with ac-bypassed level-shifting diodes. The parasitic capacitances to ground arising from the transistor terminals, level-shifting diodes, and bypass capacitors are illustrated.

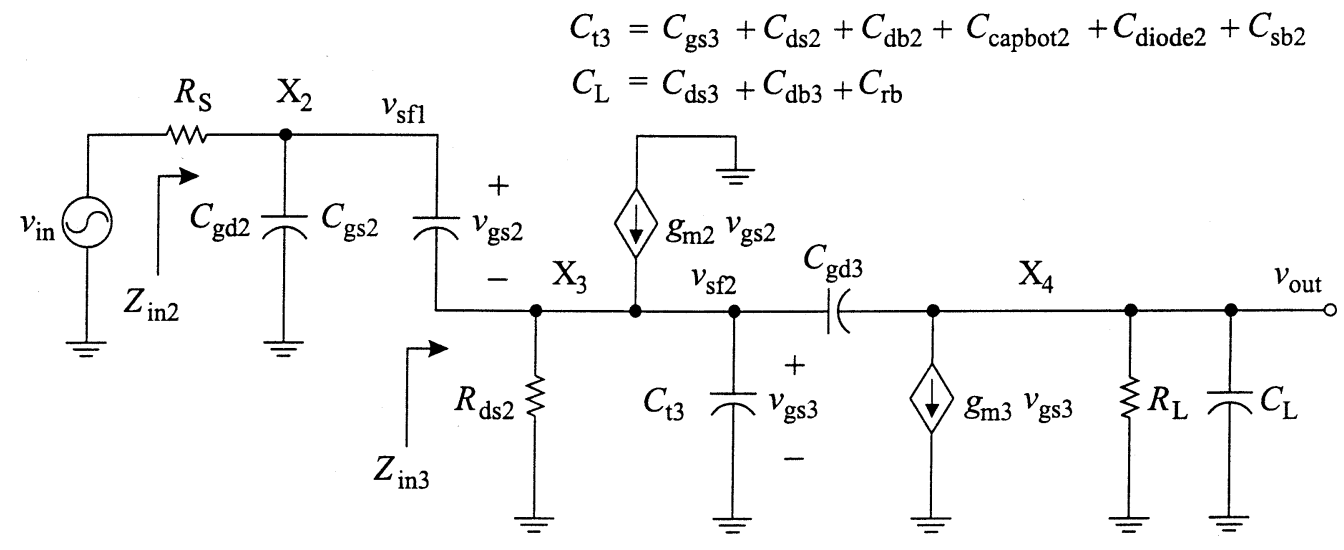

Fig. 11. Small-signal equivalent circuit used in the analytical derivation of the frequency response of a SSF-INV stage.

and the diodes introduce parasitic capacitance to ground, their relative sizes and distribution between source follower stages must be carefully considered if there is to be any bandwidth improvement from adding extra buffering. When the circuit is implemented on a very thin $28-\mu \mathrm{m}$-thick GaAs substrate, such as in the present design, the parasitics are such that a double source-follower inverter (DSF-INV) topology becomes mandatory. This arrangement is shown in Fig. 10 along with the associated diode and capacitance elements.

An analytical derivation of the frequency response of both the SSF-INV and DSF-INV gain blocks is presented in the Appendix. It demonstrates that, with the available pHEMT technology, the DSF-INV topology is optimal for meeting the output swing and bit-rate target with the minimum possible power dissipation. It should also be noted that a faster cascode inverter implementation is not feasible given the supply voltage of $-5.2 \mathrm{~V}$ and the $3-\mathrm{V}_{\mathrm{pp}}$ output swing requirement.

The transfer function of the SSF-INV is obtained by analyzing the equivalent circuit shown in Fig. 11. It includes all those components that have a significant effect on the bandwidth of the overall response, namely, the transistors' gate-to- source, gate-to-drain, source-to-bulk, and drain-to-bulk capacitance $\left(C_{\mathrm{gs}}, C_{\mathrm{gd}}, C_{\mathrm{sb}}\right.$, and $C_{\mathrm{db}}$, respectively), the final load capacitance $C_{\mathrm{L}}$, the finite impedance of the tail transistors $\left(R_{\mathrm{ds}}\right.$ and $C_{\mathrm{ds}} / C_{\mathrm{db}}$ ), and all of the bulk capacitance arising from the diodes $C_{\text {diode }}$ and bypass capacitors used to shunt them $C_{\text {capbot }}$. To simplify the notation, all of the capacitances at the source follower outputs are summed and represented as a total value $C_{\mathrm{t} n}$. The exact value of the total capacitance is dependent on several factors, namely, the number of level-shifting diodes, the size of the bypass capacitor, and the size of the three transistors that are connected to the common node. It should also be noted that the path through the diodes is considered an ideal short-circuit at high frequency, hence, there is no associated series resistance or capacitance. This assumption is valid because the bypass capacitors are large, being in the range of $2-4 \mathrm{pF}$.

In lieu of exact expressions for the poles and zeros, which are overly complex and largely uninsightful, Figs. 12 and 13 and Table II are provided to explain the operation of the circuit. Fig. 12 illustrates how the bandwidth varies as a function of the inverter to source-follower gate-width scaling, which is denoted by the parameter $p=W_{3} / W_{2}$. Clearly, the optimum bandwidth 
TABLE II

POLES AND ZEROS FOR THE SSF-INV WITH SOURCE-FOLLOWER SCALING

\begin{tabular}{|c|c|c|c|c|c|c|c|c|}
\hline \multirow[t]{2}{*}{ Stage } & \multicolumn{2}{|c|}{$p=0.75$} & \multicolumn{2}{|c|}{$p=1$} & \multicolumn{2}{|c|}{$p=2$} & \multicolumn{2}{|c|}{$p=3$} \\
\hline & poles $(\mathrm{GHz})$ & zeros $(\mathrm{GHz})$ & poles $(\mathrm{GHz})$ & zeros $(\mathrm{GHz})$ & poles $(\mathrm{GHz})$ & zeros $(\mathrm{GHz})$ & poles $(\mathrm{GHz})$ & zeros $(\mathrm{GHz})$ \\
\hline Inverter & $\left|\mathrm{p}_{1}\right|=65.2$ & $\left|z_{1}\right|=937$ & $\left|\mathrm{p}_{1}\right|=65.2$ & $\left|z_{1}\right|=937$ & $\left|\mathrm{p}_{1}\right|=65.2$ & $\left|z_{1}\right|=937$ & $\left|\mathrm{p}_{1}\right|=65.2$ & $\left|z_{1}\right|=937$ \\
\hline \multirow[t]{2}{*}{$2^{\text {nd }} S F$} & $\left|\mathrm{p}_{2}\right|=72.5$ & $\left|z_{2}\right|=89.7$ & $\left|\mathrm{p}_{2}\right|=73.4$ & $\left|z_{2}\right|=89.7$ & $\left|\mathrm{p}_{2}\right|=75.1$ & $\left|z_{2}\right|=89.7$ & $\left|\mathrm{p}_{2}\right|=75.8$ & $\left|z_{2}\right|=89.7$ \\
\hline & $\left|\mathrm{p}_{3}\right|=31.5$ & $\left|\mathrm{z}_{3}\right|=65.2$ & $\left|\mathrm{p}_{3}\right|=28.3$ & $\left|z_{3}\right|=65.2$ & $\left|\mathrm{p}_{3}\right|=20.3$ & $\left|z_{3}\right|=65.2$ & $\left|\mathrm{p}_{3}\right|=15.9$ & $\left|z_{3}\right|=65.2$ \\
\hline \multirow[t]{3}{*}{ IP VD } & $\left|\mathrm{p}_{4}\right|=71.5$ & $\left|z_{4}\right|=72.5$ & $\left|\mathrm{p}_{4}\right|=72.4$ & $\left|z_{4}\right|=73.4$ & $\left|\mathrm{p}_{4}\right|=74.3$ & $\left|z_{4}\right|=75.1$ & $\left|p_{4}\right|=75.1$ & $\left|z_{4}\right|=75.8$ \\
\hline & $\left|\mathrm{p}_{s}\right|=19.2$ & $\left|z_{s}\right|=31.5$ & $\left|\mathrm{p}_{s}\right|=20.6$ & $\left|z_{5}\right|=28.3$ & $\left|\mathrm{p}_{s}\right|=23.5$ & $\left|z_{s}\right|=20.3$ & $\left|\mathrm{p}_{s}\right|=24.7$ & $\left|z_{s}\right|=15.9$ \\
\hline & $\left|\mathrm{p}_{6}\right|=19.2$ & & $\left|\mathrm{p}_{6}\right|=20.6$ & & $\left|\mathrm{p}_{6}\right|=23.5$ & & $\left|\mathrm{p}_{6}\right|=24.7$ & \\
\hline
\end{tabular}

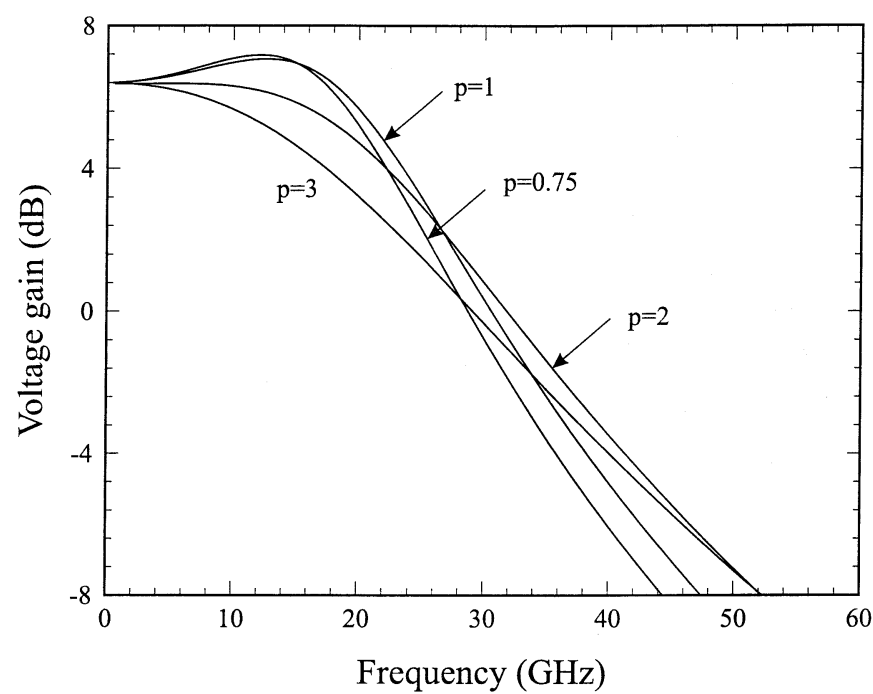

Fig. 12. Voltage gain of the SSF-INV stage as a function of frequency and of the scaling ratio $p$ between the size of the transistors in the inverter and the source follower.

occurs for values of $p$ approaching 1 . The inverter in the present example is based on the middle-stage amplifier and is scaled such that it can deliver $1.4 \mathrm{~V}$ into a load slightly greater than $50 \Omega$. Based on the transistor characteristics given in Table I, the value of $C_{\mathrm{L}}$ is $65 \mathrm{fF}$ and $C_{\mathrm{t} 3}$ varies between 185 and $320 \mathrm{fF}$ over the full range of $p$. This latter variation reflects the fact that the tail transistors, diodes, and bypass capacitors are all assumed to scale with their respective source-follower transistor.

Fig. 13 shows the transfer characteristic of the input voltage divider formed between $R_{S}$ and $Z_{\text {in2. }}$. Owing to the negative real component of the source follower's input impedance, the gain profile of this portion of the circuit exhibits a considerable amount of peaking. Table II presents the complete set of poles and zeros for each of the four values of $p$ plotted in Fig. 13. Close inspection of the table reveals that $z_{1}, z_{2}$, and $p_{2}$ are all too high to be significant, and that $p_{1}=z_{3}, p_{2}=z_{4}, p_{3}=z_{5}$ and, consequently, cancel. Thus, the overall response of the SSF-INV is defined almost entirely by the poles $p_{5}$ and $p_{6}$. Since $p_{5}$ and $p_{6}$ form a complex pair, the overall bandwidth of the SSF-INV is dependent not only on their magnitude, but on their associated damping coefficient $\zeta$ as well. In spite of the bandwidth extension afforded by the SSF-INV, it is clear from Fig. 12 that, irre-

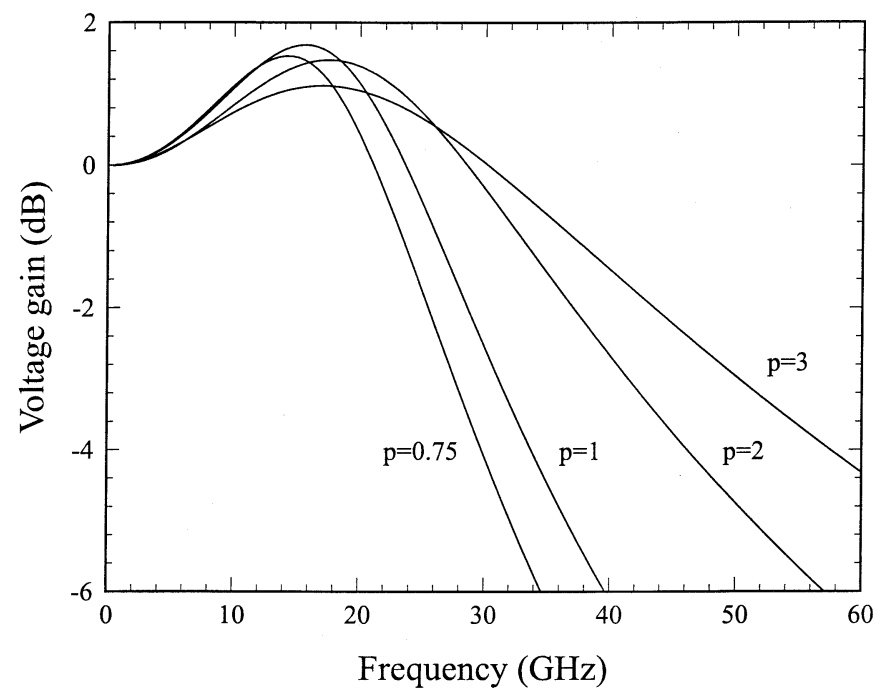

Fig. 13. Transfer function of the input voltage divider formed by the signal source impedance and the input impedance of the SSF-INV stage as a function of the scaling ratio $p$ between the size of the transistors in the inverter and the source follower.

spective of the scaling coefficient $p$, it is not possible to achieve sufficient bandwidth for $40 \mathrm{~Gb} / \mathrm{s}$ using this technology and this configuration.

The solution is to switch to a DSF-INV topology, which is represented by the equivalent model in Fig. 14 and analyzed in the Appendix. Like the SSF-INV, many of the poles and zeros in the transfer function either cancel each other or are nonsignificant. The resulting approximation, which is very nearly exact, consists of only the complex poles $p_{8}$ and $p_{9}$ and the real pole $p_{10}$.

To illustrate the effect of gate-width scaling, Figs. 15 and 16 are presented along with their associated poles and zeros in Tables III and IV. In the first instance, Fig. 15 and Table III illustrate the response when the second source follower has the same geometry $(p=1)$ as the inverter and the first source follower is scaled by an amount $k=W_{2} / W_{1}$. From Fig. 15 , the widest bandwidth of $41 \mathrm{GHz}$ is achieved for $k=2$. The degradation both above and below this value can be explained in terms of the three critical poles identified previously. Referring to Table III, $p_{8}$ and $p_{9}$ increase as $k$ is decreased, which means that the peak introduced by the negative real component of the source fol- 


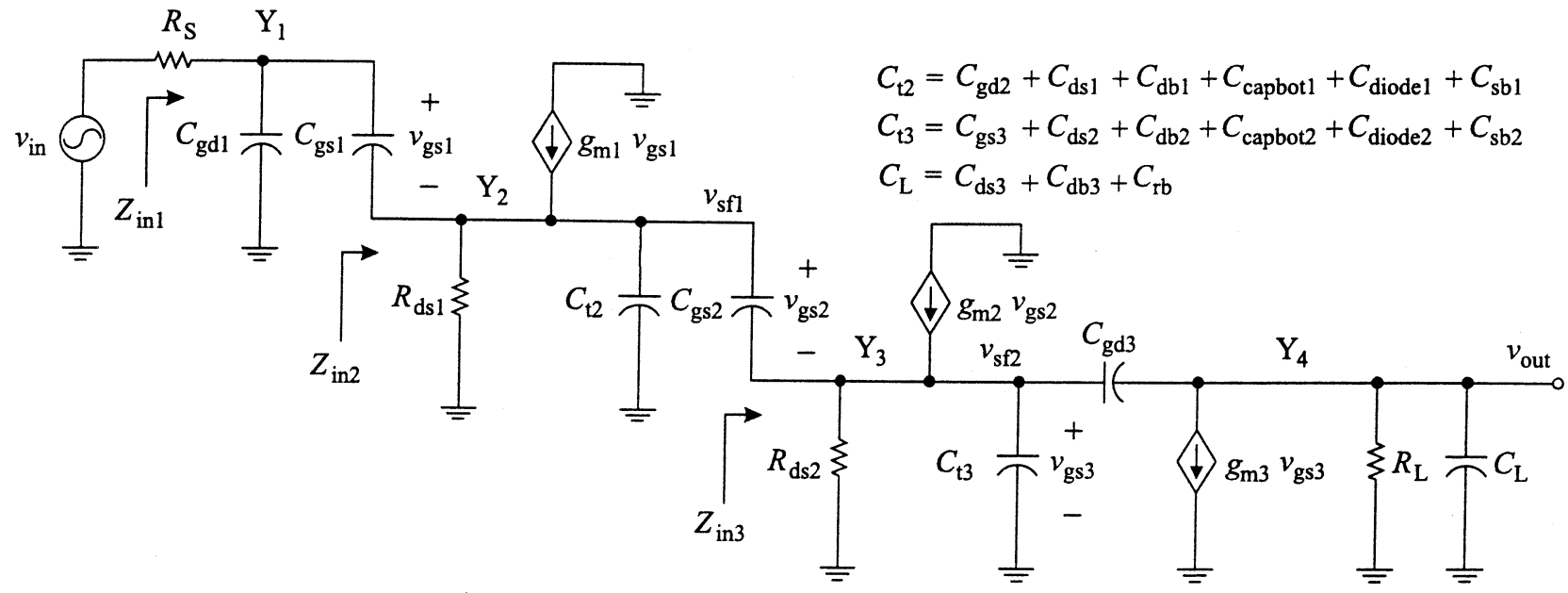

Fig. 14. Small-signal equivalent circuit used in the analytical derivation of the frequency response of a DSF-INV stage.

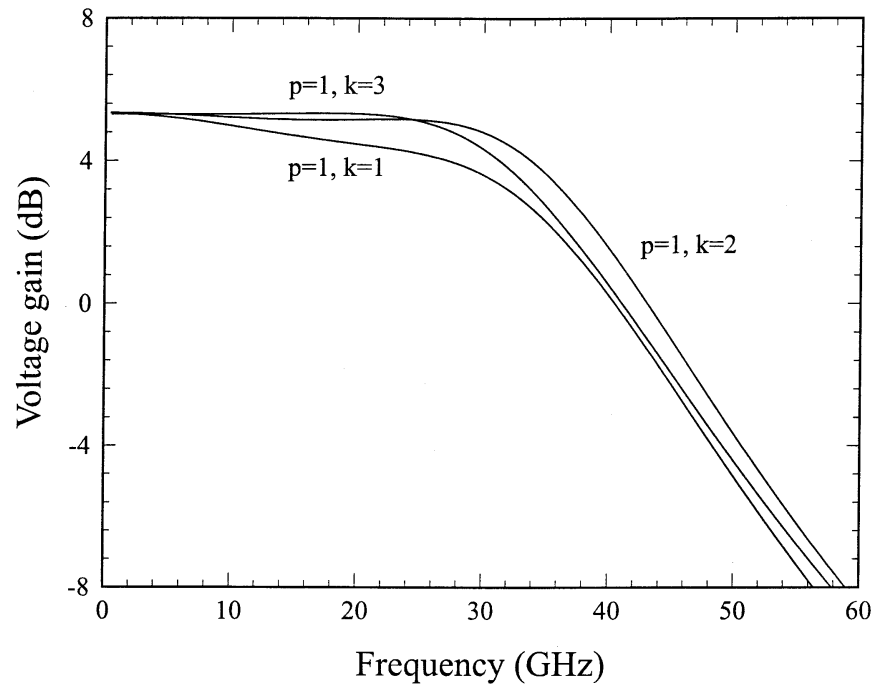

Fig. 15. Voltage gain of the DSF-INV stage as a function of frequency and of the scaling ratio $k$ between the size of the transistors in the second and first source-follower stages. The scaling ratio $p$ between the size of the transistors in the inverter and in the second source follower remains constant.

lower's input impedance moves up in frequency. At the same time, the real pole $p_{10}$ decreases. Since $p_{8}$ and $p_{9}$ increase more slowly than $p_{10}$ decreases with $k$, there is an optimum point at which the bandwidth is maximized.

The effect of varying the source-follower geometries jointly with respect to the inverter is presented in Fig. 16 and Table IV. In this case, $p=W_{3} / W_{2}, k=2$, and the optimal small-signal performance is achieved for $p=1$ and $k=2$. The explanation, in terms of the poles and zeros of Table IV, is much the same as above. The reason that the transmission response is more sensitive to variations in $p$ compared to $k$ is because the level-shifting diodes have been deployed entirely at the output of the second source follower. Consequently, any variation in $p$ will affect their size and thus the amount of parasitic capacitance that is introduced. Although not immediately obvious, it turns out that this approach has a significant advantage over distributing the diodes between the outputs of both the first and second stages. By minimizing the total capacitance at the output of the first source follower stage, the critical poles of the circuit, $p_{8}$ and

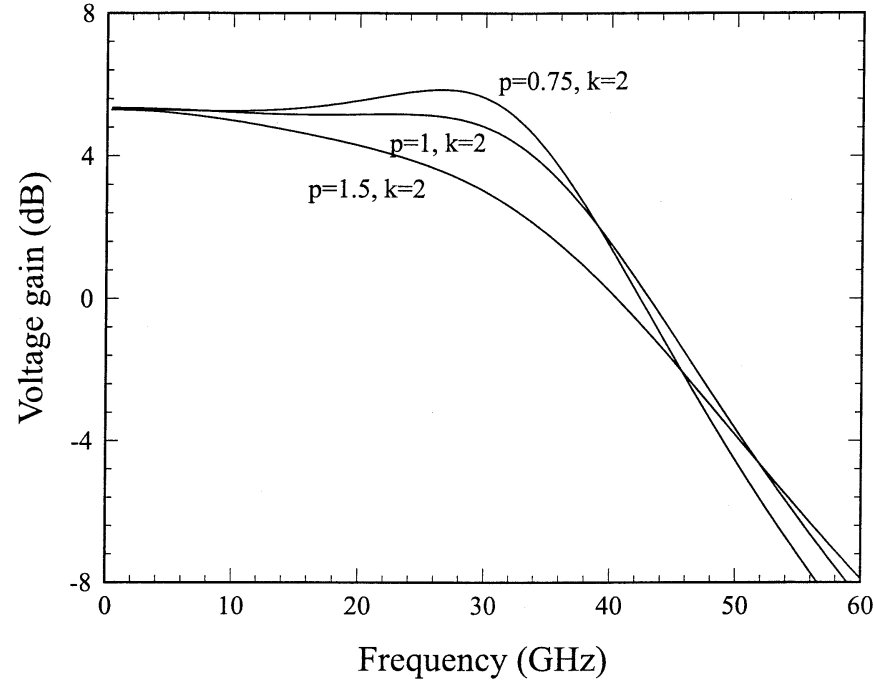

Fig. 16. Voltage gain of the DSF-INV stage as a function of frequency and of the scaling ratio $p$ between the size of the transistors in the inverter and in the second source follower. The scaling ratio $k$ between the size of the transistors in the second and first source follower stages remains constant.

$p_{9}$, are maximized for only a modest reduction in $p_{10}$. In other words, the additional source follower increases the impedance seen by the preceding inverter, reduces its capacitive loading and, therefore, regains most of the bandwidth that is lost due to the diodes and bypass capacitors.

As a final remark, small-signal bandwidth is an important figure of merit upon which to base broadband amplifier design, even if it cannot be directly applied to a limiting architecture. By carefully maximizing it while minimizing dc supply current, the amplifier is guaranteed to have good overall large-signal performance.

\section{FABRICATION}

The die, shown in Fig. 17, has dimensions of $1.95 \times 3.99 \mathrm{~mm}^{2}$ and was fabricated by Fujitsu Quantum Devices, Ltd., using a $0.15-\mu \mathrm{m}$ AlGaAs-InGaAs pHEMT process. The substrate height is $28 \mu \mathrm{m}$, and with an additional $32 \mu \mathrm{m}$ of backside metal, the IC has a total thickness of $60 \mu \mathrm{m}$. 
TABLE III

POLES AND ZEROS FOR THE DSF-INV With SOURCE FOLLOWER SCALING ONLY

\begin{tabular}{|c|c|c|c|c|c|c|}
\hline \multirow[t]{2}{*}{ Stage } & \multicolumn{2}{|c|}{$p=1, k=1$} & \multicolumn{2}{|c|}{$p=1, k=2$} & \multicolumn{2}{|c|}{$p=1, k=3$} \\
\hline & poles $(\mathrm{GHz})$ & zeros $(\mathrm{GHz})$ & poles $(\mathrm{GHz})$ & zeros (GHz) & poles $(\mathrm{GHz})$ & zeros $(\mathrm{GHz})$ \\
\hline Inverter & $\left|\mathrm{p}_{1}\right|=65.2$ & $\left|z_{1}\right|=937$ & $\left|\mathrm{p}_{1}\right|=65.2$ & $\left|z_{1}\right|=937$ & $\left|\mathrm{p}_{1}\right|=65.2$ & $\left|z_{1}\right|=937$ \\
\hline \multirow[t]{2}{*}{$2^{\text {nd }} S F$} & $\left|\mathrm{p}_{2}\right|=73.4$ & $\left|z_{2}\right|=89.7$ & $\left|\mathrm{p}_{2}\right|=73.4$ & $\left|\mathrm{z}_{2}\right|=89.7$ & $\left|\mathrm{p}_{2}\right|=73.4$ & $\left|z_{2}\right|=89.7$ \\
\hline & $\left|p_{3}\right|=28.3$ & $\left|z_{3}\right|=65.2$ & $\left|\mathrm{p}_{3}\right|=28.3$ & $\left|z_{3}\right|=65.2$ & $\left|p_{3}\right|=28.3$ & $\left|z_{3}\right|=65.2$ \\
\hline \multirow[t]{3}{*}{$1^{\text {st }} \mathrm{SF}$} & $\left|\mathrm{p}_{4}\right|=72.3$ & $\left|z_{4}\right|=89.7$ & $\left|\mathrm{p}_{4}\right|=72.4$ & $\left|z_{4}\right|=89.7$ & $\left|\mathrm{p}_{4}\right|=72.5$ & $\left|z_{4}\right|=89.7$ \\
\hline & $\left|\mathrm{p}_{5}\right|=38.7$ & $\left|z_{5}\right|=73.4$ & $\left|p_{s}\right|=32.6$ & $\left|z_{s}\right|=73.4$ & $\left|p_{s}\right|=28.8$ & $\left|z_{5}\right|=73.4$ \\
\hline & $\left|\mathrm{p}_{6}\right|=38.7$ & $\left|z_{6}\right|=28.3$ & $\left|p_{6}\right|=32.6$ & $\left|z_{6}\right|=28.3$ & $\left|\mathrm{p}_{6}\right|=28.8$ & $\left|z_{6}\right|=28.3$ \\
\hline \multirow[t]{4}{*}{ IP VD } & $\left|\mathrm{p}_{7}\right|=72.5$ & $\left|\mathrm{z}_{7}\right|=72.3$ & $\left|\mathrm{p}_{7}\right|=72.6$ & $\left|z_{7}\right|=72.4$ & $\left|\mathrm{p}_{7}\right|=72.6$ & $\left|z_{7}\right|=72.5$ \\
\hline & $\left|\mathrm{p}_{8}\right|=36.5$ & $\left|z_{8}\right|=38.7$ & $\left|\mathrm{p}_{8}\right|=36.3$ & $\left|\mathrm{z}_{8}\right|=32.6$ & $\left|\mathrm{p}_{8}\right|=34.4$ & $\left|z_{8}\right|=28.8$ \\
\hline & $\left|\mathrm{p}_{9}\right|=36.5$ & $\left|z_{9}\right|=38.7$ & $\left|\mathrm{p}_{9}\right|=36.3$ & $\left|z_{9}\right|=32.6$ & $\left|p_{9}\right|=34.4$ & $\left|z_{9}\right|=28.8$ \\
\hline & $\left|\mathrm{p}_{10}\right|=22.3$ & & $\left|\mathrm{p}_{10}\right|=25.7$ & & $\left|\mathrm{p}_{10}\right|=29.9$ & \\
\hline
\end{tabular}

TABLE IV

POLES AND ZEROS FOR THE DSF-INV WITH SOURCE-FOLLOWER-INVERTER SCALING

\begin{tabular}{|c|c|c|c|c|c|c|}
\hline \multirow[t]{2}{*}{ Stage } & \multicolumn{2}{|c|}{$p=0.75, k=2$} & \multicolumn{2}{|c|}{$p=1, k=2$} & \multicolumn{2}{|c|}{$p=1.5, k=2$} \\
\hline & poles $(\mathrm{GHz})$ & zeros $(\mathrm{GHz})$ & poles $(\mathrm{GHz})$ & zeros $(\mathrm{GHz})$ & poles $(\mathrm{GHz})$ & zeros $(\mathrm{GHz})$ \\
\hline Inverter & $\left|\mathrm{p}_{1}\right|=65.2$ & $\left|z_{1}\right|=937$ & $\left|\mathrm{p}_{1}\right|=65.2$ & $\left|z_{1}\right|=937$ & $\left|p_{1}\right|=65.2$ & $\left|z_{1}\right|=937$ \\
\hline \multirow[t]{2}{*}{$2^{\text {nd }} S F$} & $\left|\mathrm{p}_{2}\right|=72.4$ & $\left|z_{2}\right|=89.7$ & $\left|\mathrm{p}_{2}\right|=73.4$ & $\left|z_{2}\right|=89.7$ & $\left|\mathrm{p}_{2}\right|=73.4$ & $\left|z_{2}\right|=89.7$ \\
\hline & $\left|\mathrm{p}_{3}\right|=30.6$ & $\left|z_{3}\right|=65.2$ & $\left|\mathrm{p}_{3}\right|=28.3$ & $\left|z_{3}\right|=65.2$ & $\left|\mathrm{p}_{3}\right|=28.3$ & $\left|z_{3}\right|=65.2$ \\
\hline \multirow[t]{3}{*}{$1^{\text {st }} \mathrm{SF}$} & $\left|\mathrm{p}_{4}\right|=71.4$ & $\left|z_{4}\right|=89.7$ & $\left|\mathrm{p}_{4}\right|=72.4$ & $\left|z_{4}\right|=89.7$ & $\left|\mathrm{p}_{4}\right|=73.9$ & $\left|z_{4}\right|=89.7$ \\
\hline & $\left|\mathrm{p}_{5}\right|=33.8$ & $\left|z_{5}\right|=72.4$ & $\left|\mathrm{p}_{5}\right|=32.6$ & $\left|z_{5}\right|=73.4$ & $\left|\mathrm{p}_{5}\right|=30.9$ & $\left|z_{5}\right|=74.7$ \\
\hline & $\left|\mathrm{p}_{6}\right|=33.8$ & $\left|z_{6}\right|=30.6$ & $\left|\mathrm{p}_{6}\right|=32.6$ & $\left|z_{6}\right|=28.3$ & $\left|\mathrm{p}_{6}\right|=30.9$ & $\left|z_{6}\right|=24.9$ \\
\hline \multirow[t]{4}{*}{ IP VD } & $\left|\mathrm{p}_{7}\right|=71.5$ & $\left|z_{7}\right|=71.4$ & $\left|\mathrm{p}_{7}\right|=72.6$ & $\left|z_{7}\right|=72.4$ & $\left|\mathrm{p}_{7}\right|=74.0$ & $\left|\mathrm{z}_{7}\right|=73.9$ \\
\hline & $\left|\mathrm{p}_{8}\right|=33.6$ & $\left|z_{8}\right|=33.8$ & $\left|\mathrm{p}_{8}\right|=36.3$ & $\left|z_{8}\right|=32.6$ & $\left|\mathrm{p}_{8}\right|=40.7$ & $\left|\mathrm{z}_{8}\right|=30.9$ \\
\hline & $\left|\mathrm{p}_{9}\right|=33.6$ & $\left|z_{9}\right|=33.8$ & $\left|p_{9}\right|=36.3$ & $\left|z_{9}\right|=32.6$ & $\left|p_{9}\right|=40.7$ & $\left|z_{9}\right|=30.9$ \\
\hline & $\left|\mathrm{p}_{10}\right|=24.5$ & & $\left|\mathrm{p}_{10}\right|=25.7$ & & $\left|\mathrm{p}_{10}\right|=27.1$ & \\
\hline
\end{tabular}

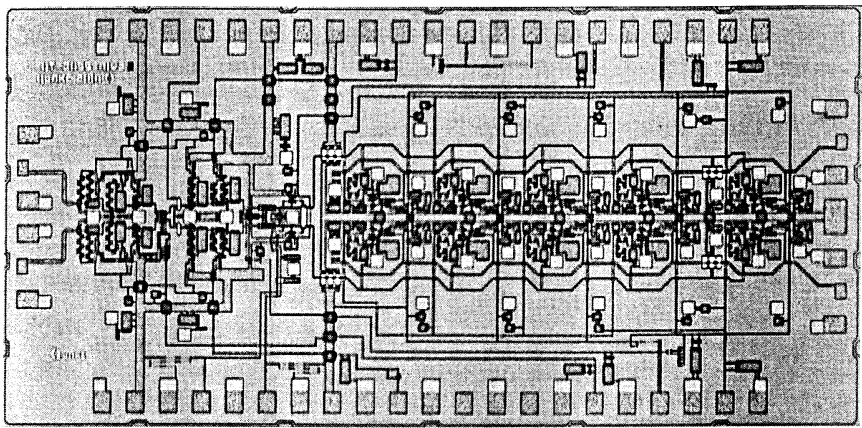

Fig. 17. Microphotograph of the EA modulator driver IC.

The process features one metal layer, an underpass layer, through-wafer vias, interdigital pHEMTs and Schottky diodes, epitaxial resistors, and MIM capacitors. The circuit itself has 240 transistors and includes on-chip bias decoupling filters.

\section{Measurement Results}

The driver circuit was measured as a bare die using an Anritsu MP1801A 43.5-Gb/s multiplexer (MUX) and an Agilent
86100 A oscilloscope with 83 484A $50-\mathrm{GHz}$ sampling heads. High-speed interconnections to and from the die were made via 65-GHz GGB wedge probes and 12-in 2.4-mm cables. In order to assess the characteristics of the test setup, preliminary measurements were performed on it without the device under test (DUT) connected. From the eye diagram shown in Fig. 18, the total jitter arising from the measurement resolution of the scope $\left(1 \mathrm{ps}_{\mathrm{rms}}\right)$, the dispersion of the high-speed interconnect and the MUX's clock jitter sum to $6.7 \mathrm{ps}_{\mathrm{pp}}$. The 12-ps $20 \%-80 \%$ rise/fall time that is also evident is partly due to the MUX output, but based on the S-parameters of the setup on its own, it is also as a result of the $16-\mathrm{GHz}$ measurement bandwidth.

The driver consumes $2.8 \mathrm{~W}$ and exhibits an overall smallsignal gain of $16 \mathrm{~dB}$ per side when it is dc coupled to an EA modulator and external load. Fig. 19 shows that the measured and simulated single-ended input and output return loss are in excellent agreement and that they are both better than $10 \mathrm{~dB}$ from 0 to $50 \mathrm{GHz}$. Although not shown, the die exhibits $60-\mathrm{dB}$ isolation up to $35 \mathrm{GHz}$, and when tested with mismatched loads, offers no evidence of instability. Simulations also suggest a differential output return loss of $15 \mathrm{~dB}$ up to $50 \mathrm{GHz}$. Figs. 20 and 21 present the measured $40-$ and $44-\mathrm{Gb} / \mathrm{s}$ eye diagrams for a 


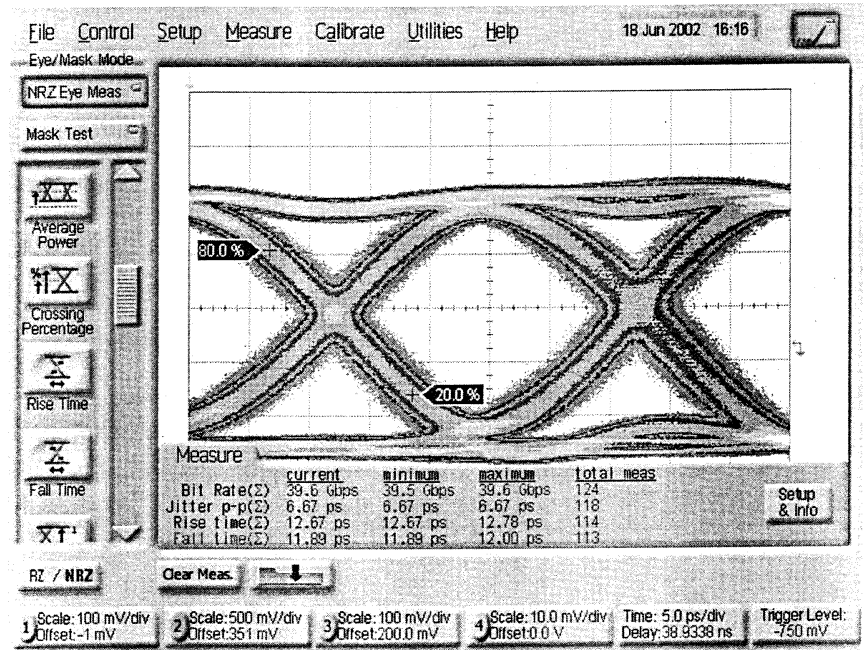

Fig. 18. Measured 40-Gb/s eye diagram with a $2^{31}-1$ pattern for the test setup without DUT.

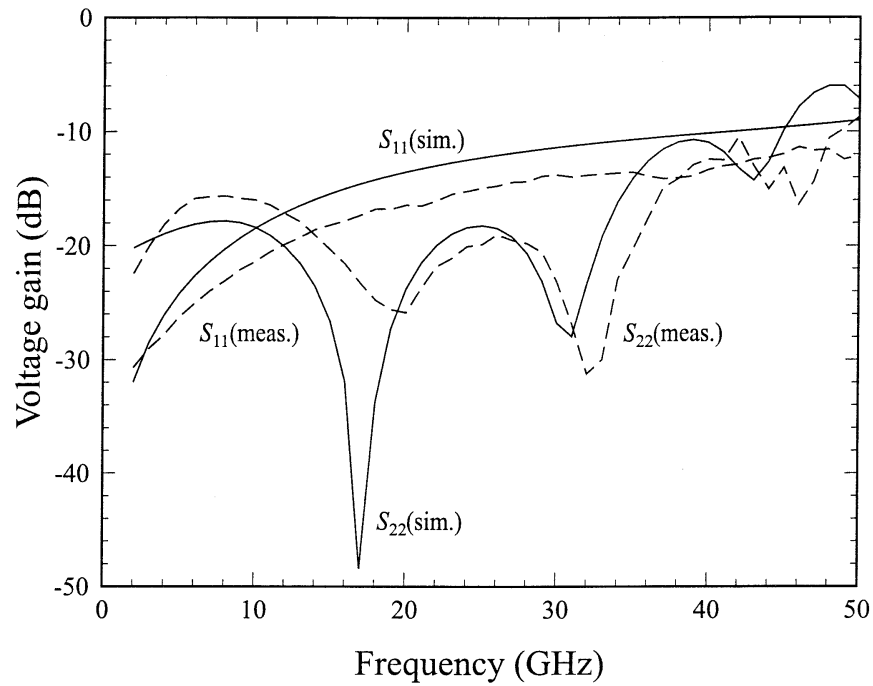

Fig. 19. Measured versus simulated input and output return loss at $18{ }^{\circ} \mathrm{C}$.

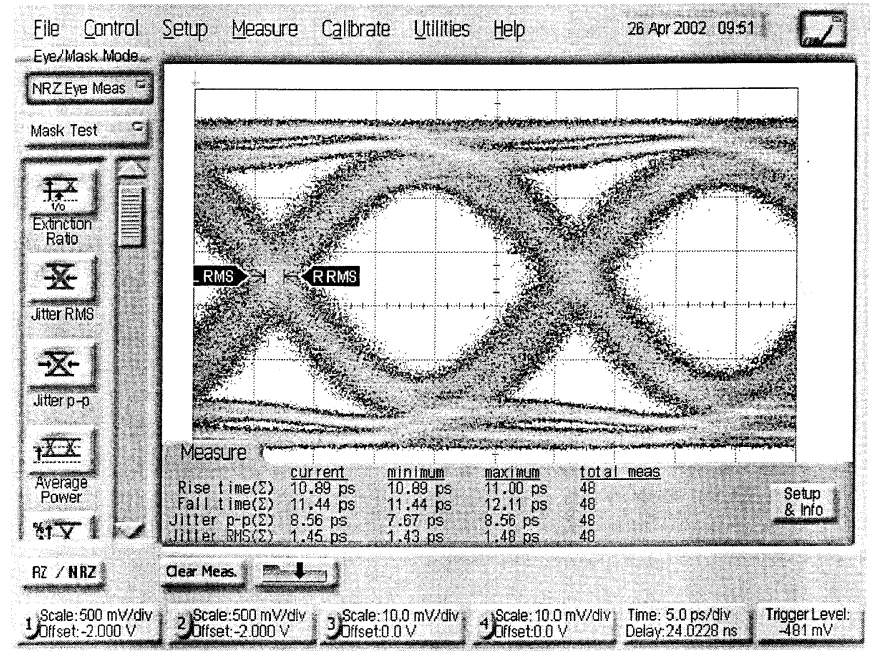

Fig. 20. Measured $40-\mathrm{Gb} / \mathrm{s}$ eye diagram with a $2^{31}-1$ pattern showing the maximum $3 \mathrm{~V}_{\mathrm{pp}}$ output swing per side.

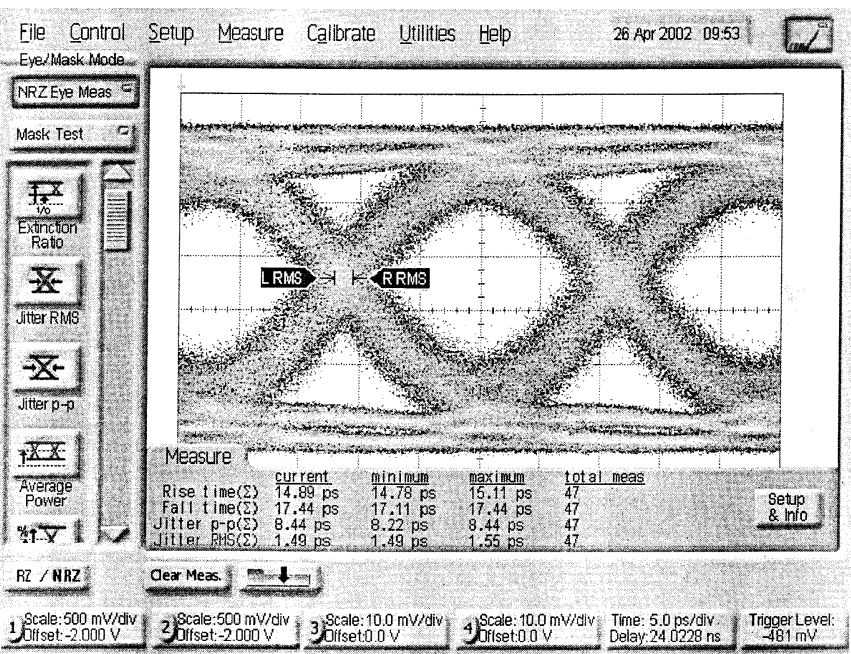

Fig. 21. Measured 44-Gb/s eye diagram with a $2^{31}-1$ pattern showing $3 V_{p p}$ output swing per side.

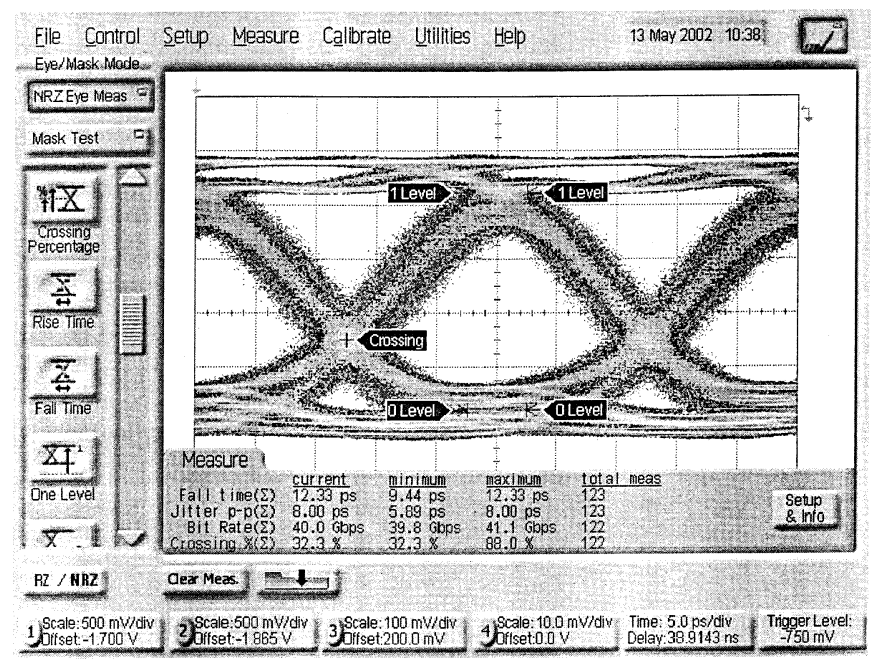

Fig. 22. Measured $40-\mathrm{Gb} / \mathrm{s}$ eye diagram with a $2^{31}-1$ pattern showing the eye crossing at $30 \%$ (pulsewidth control).

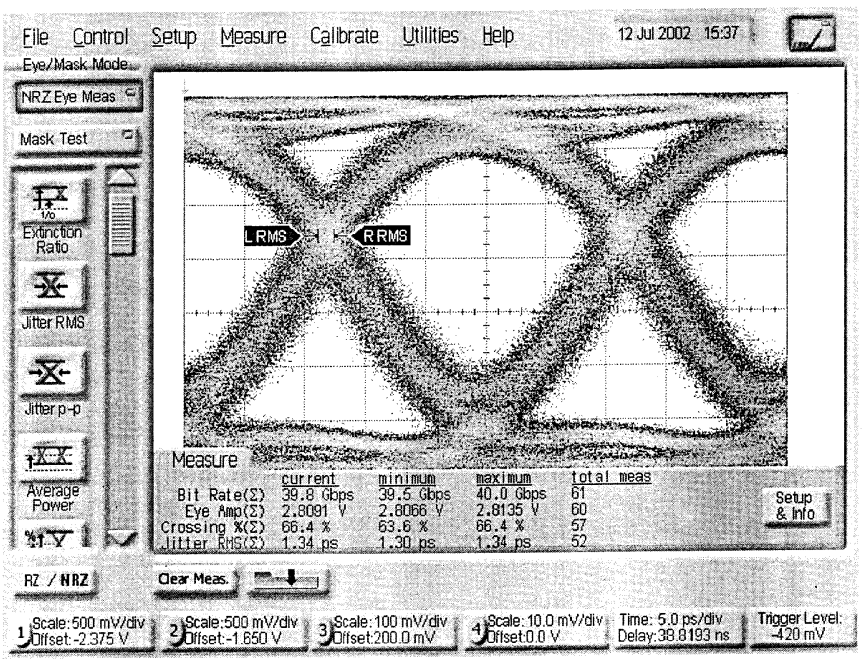

Fig. 23. Measured $40-\mathrm{Gb} / \mathrm{s}$ eye diagram with a $2^{31}-1$ pattern showing the eye crossing at $66 \%$ (pulsewidth control). 


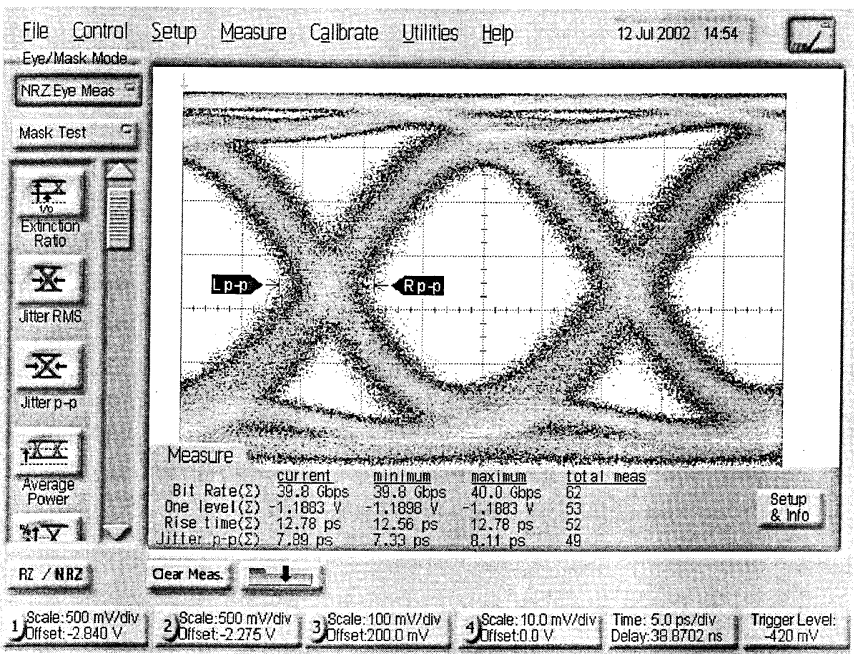

Fig. 24. Measured 40-Gb/s eye diagram with a $2^{31}-1$ pattern showing the maximum output dc offset level of $-1.1 \mathrm{~V}$.

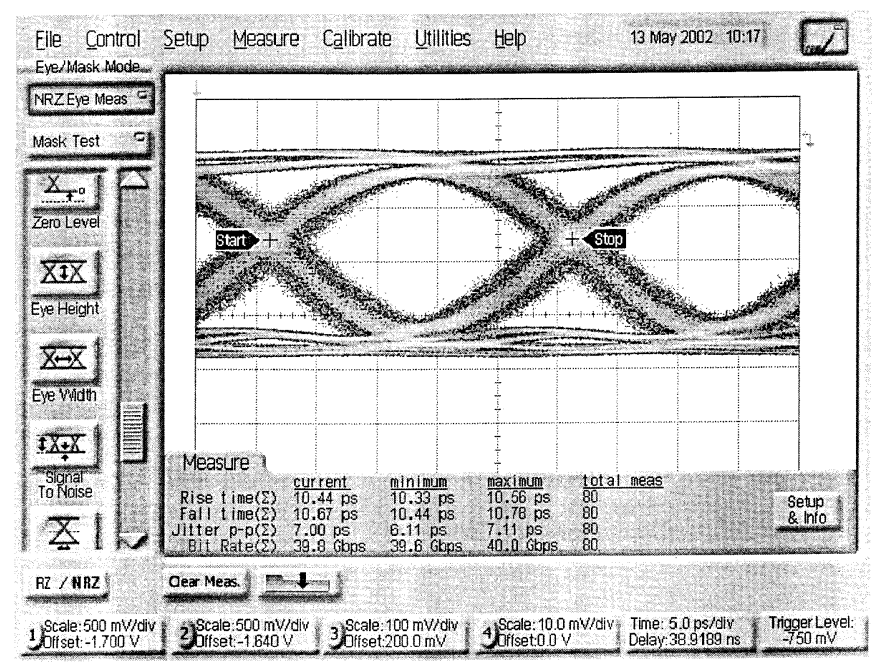

Fig. 25. Measured 40-Gb/s eye diagram with a $2^{31}-1$ pattern showing the minimum $1.7 \mathrm{~V}_{\mathrm{pp}}$ output swing per side.

$2^{31}-1$ PRBS pattern. In both cases, the output swing is $3.0 \mathrm{~V}_{\mathrm{pp}}$ per side for a differential input signal having $0.7 \mathrm{~V}_{\mathrm{pp}}$ per side. As noted above, much of the jitter present can be traced to the clock signal that is used to synchronize the oscilloscope and the uncompensated dispersion of the high-speed interconnection. The eye closure is partly the result of the limited measurement bandwidth. Since only the output cable and probe heads matter in this regard, it will be somewhat better than the $16 \mathrm{GHz}$ stated previously.

Figs. 22-25 demonstrate the EA driver control functions in operation for a differential input signal having a $2^{31}-1$ bit pattern and $0.7 \mathrm{~V}_{\mathrm{pp}}$ per side. From Figs. 22 and 23, the duty-cycle control function is shown to vary between $30 \%$ and $66 \%$. The maximum dc offset, which is defined as the level of a logic " 1 " output, is shown in Fig. 24 to be -1.1 V. This contrasts with all previous eye diagram plots, which have the minimum offset of -0.15 V. As an illustration of the output swing control, Fig. 25 depicts the measured eye diagram in the case of the minimum output swing of $1.7 \mathrm{~V}_{\mathrm{pp}}$. In both of the preceding instances, the control values can be varied smoothly between their two extremes.

\section{CONCLUSION}

A differential distributed limiting EA modulator driver IC using 0.15- $\mu \mathrm{m}$ GaAs pHEMTs has been designed and fabricated for optical transmission systems operating at data rates in the 39.8-42.8-Gb/s range. The IC achieves $3 \mathrm{~V}_{\mathrm{pp}}$ per side and features output swing control, dc offset control, and pulsewidth control. Both the circuit topology and design are based on a comprehensive analytical derivation of the frequency response of SSF-INV and DSF-INV gain blocks. The final implementation at both the gain block and die level is further optimized by means of a fully scalable nonlinear device model. Although GaAs pHEMT technology is emphasized in this paper, the principles and equations presented here can be applied to the design of many other high-speed digital circuits and logic topologies, including HBT and MOSFET common-mode logic.

\section{APPENDIX \\ DERIVATION OF THE SSF-INV AND DSF-INV FREQUENCY RESPONSE}

The derivation of the SSF-INV frequency response starts at the output, which in this context is a common-source gain block having zero source resistance (which is assumed to be incorporated into the previous stage). To determine its transfer function, KCL equations are formed at points $\mathrm{X}_{3}$ and $\mathrm{X}_{4}$ in Fig. 11 and the results equated to obtain

$$
A_{\text {inv }}=-\frac{g_{m 3} R_{\mathrm{L}}\left(1-s \frac{C_{\mathrm{gd} 3}}{g_{\mathrm{m} 3}}\right)}{1+s R_{\mathrm{L}}\left(C_{\mathrm{L}}+C_{\mathrm{gd} 3}\right)}
$$

where $C_{\mathrm{L}}$ includes the drain-to-bulk $C_{\mathrm{db}}$ and drain-to-source $C_{\mathrm{ds}}$ capacitance of the inverter transistor, as well as the parasitic capacitance to ground associated with the load resistance $C_{\mathrm{rb}}$. A similar procedure is then followed to derive the input impedance

$$
Z_{\text {in } 3}=\frac{R_{\mathrm{ds} 2}\left[1+s R_{\mathrm{L}}\left(C_{\mathrm{L}}+C_{\mathrm{gd} 3}\right)\right]}{1+a s+b s^{2}}
$$

and the coefficients in the denominator are given by

$$
\begin{aligned}
& a=R_{\mathrm{ds} 2}\left(C_{\mathrm{t} 3}+C_{\mathrm{gd} 3}^{\prime}\right)+R_{\mathrm{L}}\left(C_{\mathrm{L}}+C_{\mathrm{gd} 3}\right) \\
& b=R_{\mathrm{ds} 2} R_{\mathrm{L}}\left(C_{\mathrm{t} 3}+C_{\mathrm{gd} 3}\right)\left(C_{\mathrm{L}}+C_{\mathrm{gd} 3}\right) .
\end{aligned}
$$

To simply the expressions, all the terms associated with the Miller effect are incorporated into $C_{\mathrm{gd} 3}^{\prime}$ as follows:

$$
C_{\mathrm{gd} 3}^{\prime}=C_{\mathrm{gd} 3}\left(1+g_{\mathrm{m} 3} R_{\mathrm{L}}\right) .
$$

It should be noted that the Miller approximation is not applied in the calculation of $Z_{\text {in3 }}$. Although it does simplify (A2), it overstates the bandwidth and does little to make the subsequent expressions for this multistage amplifier any less complicated.

The determination of the transfer function of the second source follower involves forming the KCL equation at $\mathrm{X}_{3}$ and equating it to the expression for the voltage drop between $\mathrm{X}_{2}$ 
and $\mathrm{X}_{3}$. From (A2), the load is $Z_{\text {in3 }}$, which gives a transfer function of

$$
A_{\mathrm{sf} 2}=\frac{g_{\mathrm{m} 2} Z_{\mathrm{in} 3}\left(1+s \frac{C_{\mathrm{gs} 2}}{g_{\mathrm{m} 2}}\right)}{1+g_{\mathrm{m} 2} Z_{\mathrm{in} 3}\left(1+s \frac{C_{\mathrm{gs} 2}}{g_{\mathrm{m} 2}}\right)} .
$$

The complete input impedance for the source follower is now calculated in two steps. In the first instance, the KCL equation at node $\mathrm{X}_{3}$ is used to determine the equivalent impedance seen looking into the gate of the source follower's transistor. This expression is then combined in parallel with the transistors' gate-to-drain capacitance $C_{\mathrm{gd} 2}$ to yield

$$
Z_{\mathrm{in} 2}=\frac{1}{s C_{\mathrm{gd} 2}} \| \frac{1+g_{\mathrm{m} 2} Z_{\mathrm{in} 3}\left(1+s \frac{C_{\mathrm{gs} 2}}{g_{\mathrm{m} 2}}\right)}{s C_{\mathrm{gs} 2}} .
$$

Although it is possible to expand this expression, the result does not provide much insight. Moreover, as the analysis continues toward the overall input of the circuit, the equations only get more complicated.

Having determined the input impedance to the source follower, the input voltage divider has a transfer function of

$$
A_{\mathrm{vd}}=\frac{Z_{\text {in } 2}}{R_{\mathrm{S}}+Z_{\text {in } 2}}
$$

where in the general case, $R_{\mathrm{S}}$ should be replaced with $Z_{\mathrm{S}}$, the output impedance of the preceding inverter stage.

When all of the terms are combined, the result is a complete SSF-INV transfer function consisting of six poles and five zeros

$$
A_{\mathrm{v}}=A_{\mathrm{vd}} A_{\mathrm{sf} 2} A_{\mathrm{inv}}=A_{0} \frac{\prod_{\mathrm{i}=1}^{5}\left(1-\frac{s}{z_{\mathrm{i}}}\right)}{\prod_{\mathrm{i}=1}^{6}\left(1-\frac{s}{p_{\mathrm{i}}}\right)}
$$

where the dc gain term is given by

$$
A_{0}=-\frac{g_{\mathrm{m} 3} R_{\mathrm{L}}}{1+\frac{1}{g_{\mathrm{m} 2} R_{\mathrm{ds} 2}}}
$$

Up to (A6), the derivation for the DSF-INV is exactly the same as that of the SSF-INV. It diverges at (A7) because the input to the second source follower now includes the tail impedance of the first source follower in addition to the capacitance introduced by any of the level-shifting diodes that may be connected between the first and second stages. Consequently, the input impedance becomes

$$
Z_{\mathrm{in} 2}=R_{\mathrm{ds} 1}\left\|\frac{1}{s C_{\mathrm{t} 2}}\right\| \frac{1+g_{\mathrm{m} 2} Z_{\mathrm{in} 3}\left(1+s \frac{C_{\mathrm{gs} 2}}{g_{\mathrm{m} 2}}\right)}{s C_{\mathrm{gs} 2}} .
$$

Equating the KCL equation at $\mathrm{Y}_{2}$ in Fig. 14 with the voltage expression from $Y_{2}$ to $Y_{1}$, the first source-follower transfer function is

$$
A_{\mathrm{sf} 1}=\frac{g_{\mathrm{m} 1} Z_{\mathrm{in} 2}\left(1+s \frac{C_{\mathrm{gs} 1}}{g_{\mathrm{m} 1}}\right)}{1+g_{\mathrm{m} 1} Z_{\mathrm{in} 2}\left(1+s \frac{C_{\mathrm{gs} 1}}{g_{\mathrm{m} 1}}\right)}
$$

In a procedure similar to that followed in the derivation of (A7), the input impedance of the first source follower is given by

$$
Z_{\mathrm{in} 1}=\frac{1}{s C_{\mathrm{gd} 1}} \| \frac{1+g_{\mathrm{m} 1} Z_{\mathrm{in} 2}\left(1+s \frac{C_{\mathrm{gs} 1}}{g_{\mathrm{m} 1}}\right)}{s C_{\mathrm{gs} 1}}
$$

and permits the determination of the response of the DSF-INV's input voltage divider

$$
A_{\mathrm{vd}}=\frac{Z_{\text {in } 1}}{R_{\mathrm{S}}+Z_{\text {in } 1}}
$$

Combining all of the individual gain terms, the overall transfer function for the DSF-INV consists of a dc gain term, ten poles, and nine zeros

$$
A_{\mathrm{v}}=A_{\mathrm{vd}} A_{\mathrm{sf} 1} A_{\mathrm{sf} 2} A_{\mathrm{inv}}=A_{0} \frac{\prod_{\mathrm{i}=1}^{9}\left(1-\frac{s}{z_{\mathrm{i}}}\right)}{\prod_{\mathrm{i}=1}^{10}\left(1-\frac{s}{p_{\mathrm{i}}}\right)}
$$

where the familiar expression for the dc gain has been singled out as

$$
A_{0}=-\frac{g_{\mathrm{m} 3} R_{\mathrm{L}}}{\left(1+\frac{1}{g_{\mathrm{m} 1} R_{\mathrm{ds} 1}}\right)\left(1+\frac{1}{g_{\mathrm{m} 2} R_{\mathrm{ds} 2}}\right)} .
$$

When all of the terms in (A9) and (A15) are expanded, it becomes possible to solve the resulting polynomial expressions to arrive at the complete set of poles and zeros presented in Tables II-IV.

\section{ACKNOWLEDGMENT}

The authors would like to thank Fujitsu Quantum Devices, Ltd., for fabricating the die and their colleagues H. Tran, D. Viorel, and S. Szilagyi for their valuable contributions.

\section{REFERENCES}

[1] Y. Baeyens, G. Georgiou, J. Weiner, V. Houtsma, P. Paschke, Q. Lee, A. Leven, R. Kopf, J. Frackoviak, C. Chen, C. T. Liu, and Y. K. Chen, "InP D-HBT ICs for $40 \mathrm{~Gb} / \mathrm{s}$ and higher bitrate lightwave transceivers," in IEEE GaAs IC Symp. Dig., Baltimore, MD, Oct. 2001, pp. 125-128.

[2] G. Freeman, Y. Kwark, M. Meghelli, S. Zier, A. Rylyakov, M. Sorna, T. Tanji, O. Schreiver, K. Walter, J. Rieh, B. Jagannathan, A. Joseph, and S. Subbanna, " $40 \mathrm{Gbit} / \mathrm{sec}$ circuits built from a $120 \mathrm{GHz} f_{\mathrm{T}} \mathrm{SiGe}$ technology," in IEEE GaAs IC Symp. Dig., Baltimore, MD, Oct. 2001, pp. 89-92.

[3] M. Racanelli, K. Schuegraf, A. Kalburge, A. Kar-Roy, B. Shen, C. Hu, D. Chapek, D. Howard, D. Quon, F. Wang, G. U'ren, L. Lao, H. Tu, J. Zheng, J. Zhang, K. Bell, K. Yin, P. Joshi, S. Akhtar, S. Vo, T. Lee, W. Shi, and P. Kempf, "Ultra high speed SiGe NPN for advanced BiCMOS technology," in IEDM Tech. Dig., Washington, DC, Dec. 2001, pp. 336-339.

[4] A. Joseph, D. Coolbaugh, D. Harame, G. Freeman, S. Subbanna, M. Doherty, J. Dunn, C. Dickey, D. Greenberg, R. Groves, M. Meghelli, A. Rylyakov, M. Sorna, O. Schreiber, D. Herman, and T. Tanji, "0.13 $\mu \mathrm{m}$ $210 \mathrm{GHz} f_{\mathrm{T}}$ SiGe HBTs-Expanding the horizons of SiGe BiCMOS," in IEEE Int. Solid-State Circuits Conf. Dig. Tech. Papers, San Francisco, CA, Feb. 2002, pp. 180-181.

[5] D. Streit, R. Lai, A. Gutierrez-Aitken, M. Siddiqui, B. Allen, A. Chau, W. Beale, and A. Oki, "InP and GaAs components for 40 GBPS applications," in IEEE GaAs IC Symp. Dig., Baltimore, MD, Oct. 2001, pp. $247-250$.

[6] H. Shigematsu, N. Yoshida, M. Sato, N. Hara, T. Hirose, and Y. Watanabe, " $45-\mathrm{GHz}$ distributed amplifier with a linear 6- $\mathrm{V}_{\mathrm{p}-\mathrm{p}}$ output for a $40-\mathrm{Gb} / \mathrm{s} \mathrm{LiNbO}_{3}$ modulator driver circuit," in IEEE GaAs IC Symp. Dig., Baltimore, MD, Oct. 2001, pp. 137-140. 
[7] M. Miyashita, N. Yoshida, Y. Kojima, T. Kitano, N. Higashisaka, J. Nakagawa, T. Takagi, and M. Otsubo, "An AlGaAs/InGaAs pseudomorphic HEMT modulator driver IC with low power dissipation for $10-\mathrm{Gb} / \mathrm{s}$ optical transmission systems," IEEE Trans. Microwave Theory Tech., vol. 45, pp. 1058-1064, July 1997.

[8] T. Y. K. Wong, A. P. Freundorfer, B. C. Beggs, and J. E. Sitch, "A 10-Gb/s AlGaAs-GaAs HBT high power fully differential limiting distributed amplifier for III-V Mach-Zehnder modulator," IEEE J. SolidState Circuits, vol. 31, pp. 1388-1393, Oct. 1996.

[9] M. Miyashita, K. Yamamoto, K. Andoh, N. Okada, K. Motoshima, and A. Takemoto, "A 10-Gb/s AlGaAs/InGaAs pHEMT distributed EA driver with a D-flip-flop for optical fiber links," in IEEE GaAs IC Symp. Dig., Seattle, WA, Nov. 2000, pp. 205-208.

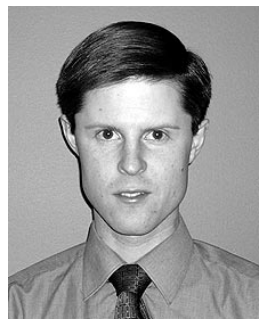

Douglas S. McPherson (S'99-M'00) was born in Ottawa, ON, Canada, in 1973. He received the B.S. degree in engineering physics from Queen's University, Kingston, Canada, in 1995, the M.S. degree in electrical engineering from Carleton University, Ottawa, in 1998, and the Ph.D. degree in electrical engineering from the University of Surrey, Guildford, U.K., in 2001. His Doctoral and Master's research focused on the design of novel millimeter-wave MMICs for communications and automotive radar applications.

From 1991 to 2001, he held various research positions at Nortel Networks Carling Laboratories, the Government of Canada's Communications Research Center, and the British Broadcasting Corporation R\&D Center at Kingswood Warren, Kingswood, U.K. In 2001, he joined Quake Technologies, Ottawa, as an Analog Design Engineer, where he is involved in developing high-speed analog circuits for $10-$ and $40-\mathrm{Gb} / \mathrm{s}$ physical layer ICs. His current research interests include EAM drivers, transimpedance amplifiers, and FFE/DFE electronic dispersion compensation circuits.

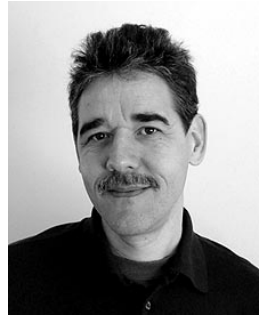

Florin Pera (M'97) received the Diploma of Engineering in electronics from the Polytechnic Institute of Bucharest, Bucharest, Romania, in 1985 and the M.S. degree in electrical engineering from the University of Montreal, Montreal, QC, Canada, in 1997.

From 1983 to 1985, he studied various techniques for processing silicon opto-electronic receiver and solar cell devices. From 1985 to 1995, he worked in research and development in Romania and Montreal, as an Analog IC Designer for low-voltage low-power RF applications and high-speed series digital ICs. $\mathrm{He}$ also worked in the area of RF module design and microwave module evaluation. He then spent two years developing automatic routing techniques for high-speed ICs for the Microelectronics Research Group, Montreal, and the Design Workshop Ltd., Montreal. From 1997 to 2001, he was with Nortel Networks, Ottawa, Canada, designing high-speed integrated circuits for SONET OC-48, OC-192, and OC-768 systems using BiCMOS and SiGe HBT technologies. In 2001, he joined Quake Technologies, Ottawa, as Principal Designer and Leader of the electro-optical interface IC design team. While at Quake, he was instrumental in the design of high-gain integrated TIA/LAs, VCSEL drivers, and EA modulator drivers for both 10 - and $40-\mathrm{Gb} / \mathrm{s}$ systems, using BiCMOS, InP HBT, and GaAs pHEMT technologies. He also participated in the development of a $10 \mathrm{G}$ Ethernet PHY transceiver and a $40-\mathrm{Gb} / \mathrm{s}$ SerDes. He is currently with Insyte (Innovative Systems and Technologies) Corporation, Ottawa, where his main responsibilities and research interests concern the development of high-performance analog and mixed-signal ICs for wireless, wireline, and optical data communication applications.

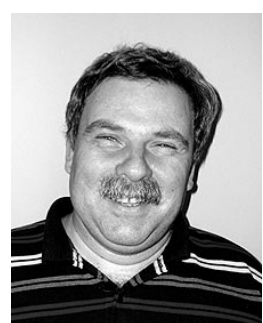

Mihai Tazlauanu received the Ph.D. degree in electrical engineering from the Polytechnic University of Bucharest, Bucharest, Romania, in 1995, and the Ph.D. degree in physics from the University of Montreal, Montreal, QC, Canada, in 1997.

For ten years, he was with the Quality and Reliability Department, R\&D Institute for Microelectronics, Bucharest. In 1996, he joined Semiconductor Insights, Ottawa, Canada, where he was involved in process analysis and the development of leading-edge semiconductor technologies. Since 2001, he has been with Quake Technologies, Ottawa, where he has been responsible for device evaluation and modeling and reliability qualification. His research interests include RF model extraction for active and passive devices produced in sub-quarter-micron $\mathrm{CMOS}, \mathrm{SiGe}$, and III-V processes.

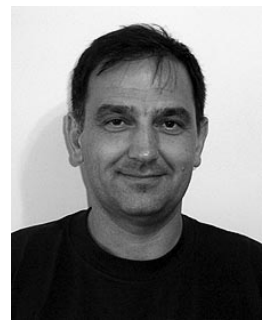

Sorin P. Voinigescu (S'92-M'91-SM'02) received the M.Sc. degree in electronics from the Polytechnic Institute of Bucharest, Bucharest, Romania, in 1984 and the Ph.D. degree in electrical and computer engineering from the University of Toronto, Canada, in 1994. His Ph.D. dissertation was on the design and fabrication of VLSI compatible Si/SiGe p-MOSFETs.

From 1984 to 1991, he worked in research and development and in academia in Bucharest, designing and lecturing on microwave semiconductor devices and microwave integrated circuits. From 1994 to 2000, he was with Nortel Networks, Ottawa, Canada, where he was responsible for projects in high-frequency characterization and statistical scalable compact model development for $\mathrm{Si}, \mathrm{SiGe}$, and III-V heterostructure devices. He led the modeling infrastructure development for, and was involved in the prototyping of, wireless and broad-band fiber optics transceivers in emerging semiconductor technologies. In April 2000, he cofounded Quake Technologies, Ottawa, a fabless semiconductor company focusing on the design and fabrication of 10- and 40-Gb/s physical layer ICs. As Chief Technology Officer of Quake, he coordinated the access and characterization of $\mathrm{Si}, \mathrm{SiGe}, \mathrm{GaAs}$, and InP technologies, high-frequency package design, and electro-optical interface product development. In September 2002, he joined the Department of Electrical and Computer Engineering, University of Toronto, as an Associate Professor. He has authored or coauthored more than 30 refereed and invited technical papers spanning the simulation, modeling, design, and fabrication of GaAs-, InP-, and Si-based heterostructure devices and circuits and holds two U.S. patents in these areas. His research and teaching interests focus on the modeling and characterization of very deep-submicron semiconductor devices and on novel design techniques and low-voltage low-power topologies for wireless, optical fiber, and wireline data communication physical layer ICs in the $10-100-\mathrm{GHz}$ range.

Dr. Voinigescu was a corecipient of the Best Paper Award from the 2001 IEEE Custom Integrated Circuits Conference. He is a member of the technical program committee of the IEEE GaAs IC Symposium. 